\title{
Application of multi-modal 2D and 3D imaging and analytical techniques to document and examine coins on the example of two Roman silver denarii
}

\author{
Mona Hess ${ }^{*^{*} \mathbb{D}}$, Lindsay W. MacDonald ${ }^{2} \mathbb{D}$ and Jaroslav Valach ${ }^{3}$
}

\begin{abstract}
This case study is applying imaging and analytical techniques from multiple scientific disciplines to digitise coins and evaluate 3D multi-modal visualisation. Two ancient Roman silver denarii were selected as test objects to establish whether the proposed digital recording methods can support professional numismatic comparison of features and properties. The coins raise questions concerning their provenance, authenticity, design, purpose of issue and historic usage, but they also pose considerable recording challenges due to their material and surface properties, which are the main focus in this paper. The coins have been examined by the following techniques: dome photography for image sets for PTM/RTI visualisation and photometric stereo; X-ray microtomography for detection of cracks or impurities; Scanning Electron Microscopy for detailed surface investigation; Energy-Dispersive X-ray Spectroscopy for elemental analysis; micro X-ray fluorescence spectrometry mapping; 3D laser and structured light scanning for 3D spatial capture; photogrammetry/structure from motion, focus-stacking. The results indicate the feasibility of such techniques for museum documentation and as contribution to scientific examination of coins in general.
\end{abstract}

Keywords: 3D scanning, Focus-stacking, MicroCT, Numismatic, Photogrammetry, Photometric stereo, PTM/RTI, SEM/ EDX, SFM, XRF

\section{Background}

Multi-modal 2D and 3D imaging together with other analytical techniques were applied to document and examine coins, an approach that has been demonstrated in other Heritage Science projects [1]. The case study was undertaken by a group of scientists, cultural heritage researchers, conservators and museum professionals participating in the European network, Colour and Space in Cultural Heritage $(\mathrm{COSCH})$, supported by the programme for European Cooperation in Science and Technology (COST-Action TD1201) [2].

\footnotetext{
*Correspondence: Mona.Hess@uni-bamberg.de

${ }^{1}$ Digital Technologies in Heritage Conservation, Institute of Archaeology, Heritage Conservation and Art History, Otto-Friedrich University of Bamberg, Am Zwinger 4, 96047 Bamberg, Germany

Full list of author information is available at the end of the article
}

The test objects for this study were two silver denarii (Coins A and B) portraying Empress Favstina I, wife of Antoninus Pius, believed to be posthumous deification issues of $141 \mathrm{AD}$. The obverse of both coins shows the bust of the empress, facing right, with raised inscription DIV $\Lambda$ F $\Lambda$ VSTIN $\Lambda$. The portrayal on Coin $\mathrm{A}$ is rather more flattering to a lady who was famous for her beauty. The designs on the reverse faces are different: Coin A shows Aeternitas (or perhaps Urania) holding a globe in her right hand, with palla billowing out around her head, and is inscribed $\Lambda$ ETER-NIT $\Lambda S$; Coin B shows Vesta, holding the palladium in her right hand, sceptre in left, and is inscribed VES-T $\Lambda$. Each coin is approximately $17 \mathrm{~mm}$ in diameter and $1.5 \mathrm{~mm}$ thick (see Fig. 1). These two ancient Roman silver denarii were selected as test objects to establish whether the proposed optical and spectrometric recording methods and techniques could support professional comparison of features and 

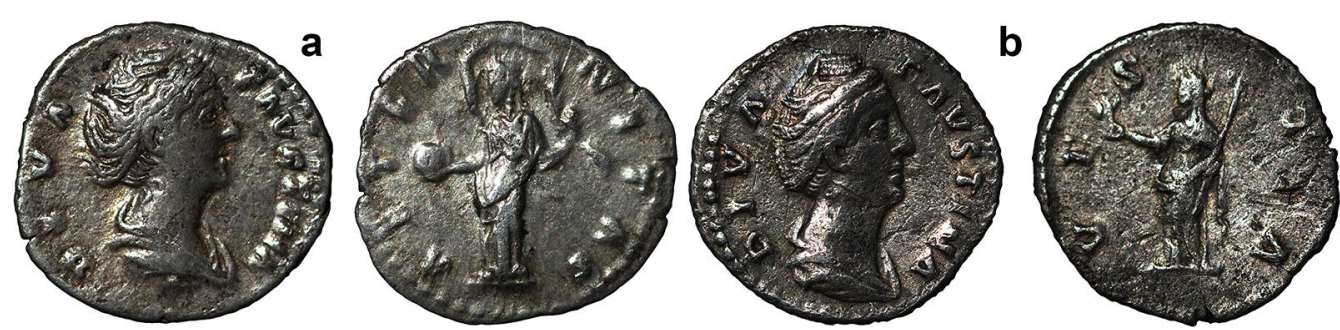

Fig. 1 Photograph of obverse and reverse of two silver Roman denarii (a, b) depicting Diva Favstina (Lindsay W. MacDonald, UCL)

properties. The coins, as example for this type of object, raise questions concerning their provenance, authenticity, design, purpose of issue and historic usage which have been explored elsewhere. They also pose considerable recording challenges due to their material and surface properties which shall be the main focus of this paper. This article is a report of the case study project and it reviews the techniques employed and summarises the results.

From a joint meeting with numismatists the following tasks for archaeologists, curators and conservators receiving new coins in their collection became evident (from personal communication from the COSCH Roman Case study meeting on 22 June 2016 at University College London. Participants, see Acknowledgements):

(a) Knowledge about the archaeological context of the coins, including provenance, site, stratigraphic layer, environment accrual, which also helps dating and authentication;

(b) Gentle cleaning and conservation of the surface for identification and cataloguing of coins, especially if found in large quantities (e.g., a block-lifted hoard), as well as information about readability and stability of the coin;

(c) Knowledge about type of a coin (e.g., portray, legend, border, flipping; shape, diameter, thickness, weight) and changes in time, as well as wear, corrosion and dirt classification;

(d) Identification and comparison of die patterns and tool marks, for information about provenance and workshops; Banker marks, for historical quality control and validation; Mutilation marks, for validation, dislike of emperor, or loss of currency value;

(e) Information about material composition, including elemental characterization (e.g., percentage of silver), which helps to determine origination and to understand economic, political, social issues, such as production, trade, migration, enriching surface layer or forgery; (f) Attribution, classification and description, for research and accessioning into the collection;

(g) Examination of authenticity and significance of a coin;

(h) More intense cleaning and conservation towards documentation for an exhibition or specific publication;

(i) Production of visual and analytical evidence/imagery for research, publication and dissemination;

(j) Storage of the information in a searchable database.

From these interviews it could also be concluded that numismatic collections continue to rely on traditional documentation and analysis methods, predominantly manual measurements and 2D photography, which have limited information in terms of dimensional and spectroscopic information. It could also be confirmed that advanced non-destructive methods for recording and examination have increasingly been introduced to conservation and museum practices, in order to complement traditional documentation and analytical techniques, with a view to automation on some of the tasks named above, but are not the norm.

This paper summarises outcomes that can be gleaned for numismatics by the use of different heritage science methods and techniques (non-destructive imaging, physico-chemical analyses, but also conservation and data management) used on the exemplary Roman coins, can contribute to meet the tasks of numismatists named above.

\section{Techniques and methods for documentation and analysis of coins}

Firstly, a methodology and workflow was developed for the study. Steps towards a rigorous procedure for documentation include reason(s)/question(s), planning, multimodal data collection, data analysis (extracting knowledge) and interpretation of results according to the questions. Of course, the aims for acquiring data should be clear from the beginning. The availability of particular 
collaborators and equipment at particular times in this case study, as in every project, affected the order, type, and dates of data acquisition (see Fig. 2, [3]).

The following challenges were faced by optical techniques for the selected Roman coins: surface properties, small size, shallow relief, and metallic specularity. This section will first describe the techniques used to document and analyse the coins: (a) hands-on inspection and drafting; subsequently selected optical and spectrometric techniques were employed to record the surface details and internal structure of the coins and in particular (b) optical non-destructive examination and 3D recording, also including photography and (c) complementary physico-chemical methods for material analysis.

\section{Hands-on inspection and drafting}

Coins found on archaeological sites are typically documented by manual drawings, because the draftsman uses his or her judgement to draw only the relevant details. Finds generally have signs of wear, dirt, corrosion, etc. and therefore line drawings have also found widespread use as illustrations in coin catalogues. Digital photography and 2D document scanning with textual accompanying annotation is used to create records of coins, please see below. The finds have to be documented properly, because in general they cannot legally be taken outside the country hosting the excavation.

The study of a coin's features has traditionally been conducted by direct hands-on examination, employing magnification tools and a strong directional light source.

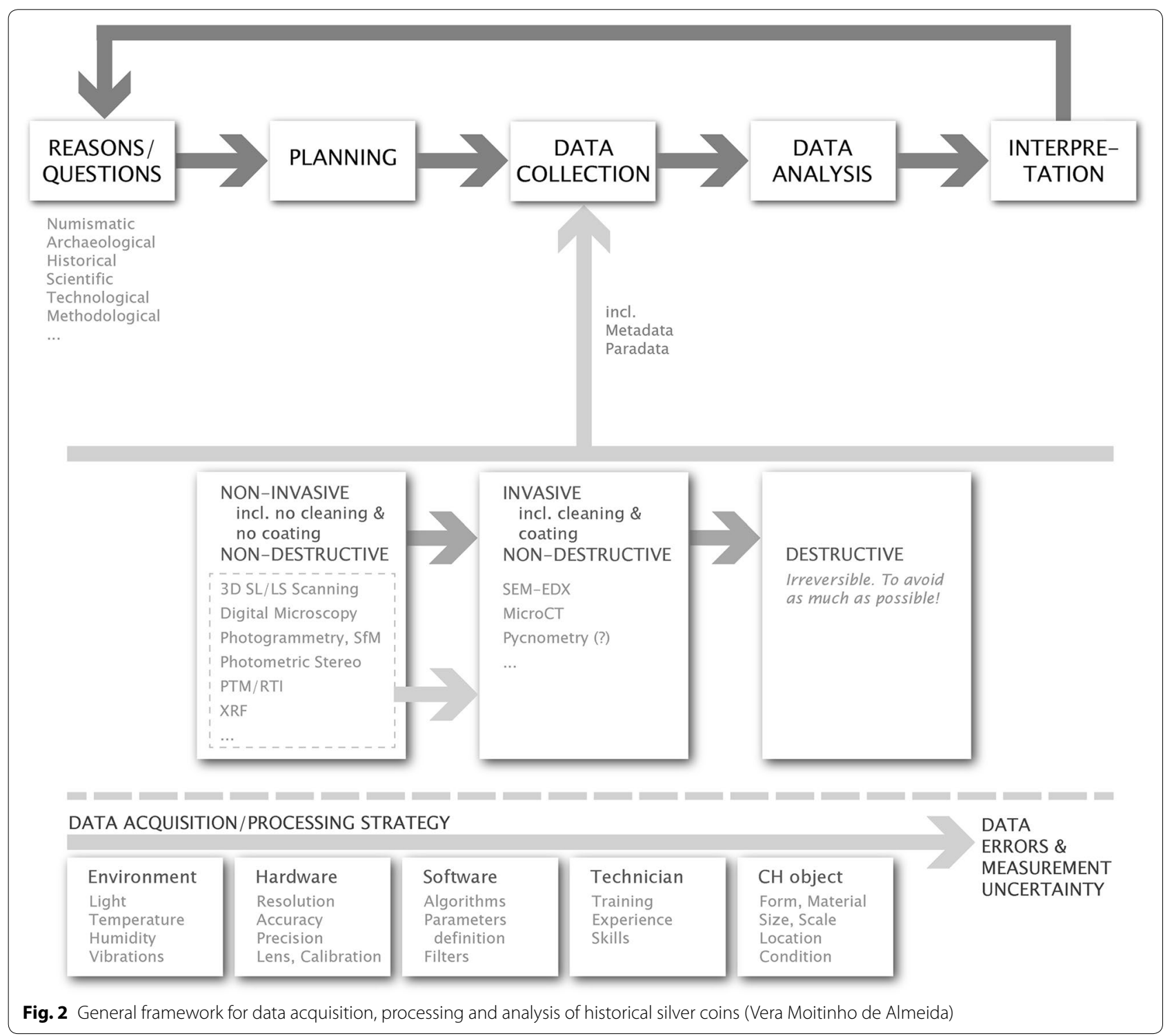


By holding the coin under the light, and tilting it relative to the viewing direction, the surface features may be discerned. Unfortunately, security concerns due to the ease of concealment, lack of unique identification, and often high resale value severely limit opportunities for this method of examination. When coins are secured in glass cabinets, even those employing mirrors and magnifying optics, the ability to perceive surface relief is significantly reduced. The quality of numismatic information that can be gleaned from a coin decreases further if in-person examination is not possible. Traditional photographic documentation conveys only a subset of the information discernible through direct physical inspection [4].

\section{Optical non-destructive examination and 3D recording Photography}

Widely used in numismatic research and for publication illustration purposes, the use of $2 \mathrm{D}$ photography is the most convenient means of documentation and visualisation of coins.

In the documentation of coins, images provide additional information besides the written description, conveying both the visual design and the state of preservation. Traditionally coins have been photographed by numismatists as $2 \mathrm{D}$ monochrome images, and these are of great qualitative value. But unless a standardized configuration of illumination is employed, it is difficult to use the images for quantitative analysis and comparison. For imaging of pre-modern coins, for example, numismatic photographers have sometimes employed a light source inclined at an angle from the optical axis of the camera. This has the advantage of reducing the direct specular reflections from the metallic surface, but it produces bright reflections from gradients on one side of relief features and shadows on the other. An example of photographs of the two Roman coins is shown in Fig. 1 . The images were taken by a Nikon D200 camera using a single flashlight to the upper left at an elevation of approximately $60^{\circ}$, giving a high-contrast image with good rendering of surface relief.

This asymmetrical rendering, which depends on both illumination and viewing angles, makes it difficult to decide whether a coin was minted by the same die. In general, the intensity, direction, and number of light sources may vary from one studio to another, leading to differences in the shadows cast, the contrast between bright and dark regions, and the rendering of surface texture. Different lighting directions may make small patterns on the coin, such as inscriptions and symbols, look very different, and highlights arising from specularity of the metallic surface may affect the quality of the images, especially when automatic exposure correction is enabled in the camera. The use of polarizing filters to reduce specular highlights can cause undesirable birefringence effects [4]. More fundamentally, the projection of the 3D object surface onto the $2 \mathrm{D}$ image means that valuable information about the object is discarded, which makes it more difficult to analyse distortions arising from the striking of the coin in the die and also of subsequent wear and corrosion [5].

Because of the relatively small size, shallow relief, and metallic specularity of most coins, special techniques are needed for photography. In addition to a reproduction table with two light sources at changeable angles from the side and a DSLR camera with a good macro lens, careful attention needs to be paid to the geometry of the incident illumination. In general, the raised areas of the surface need to be rendered in the image by tones different from those of the ground plane of the coin. This cannot be achieved in most cases by a single light source at an oblique angle, as in Fig. 1, because for a shiny surface the light is reflected away from the camera, making it appear too dark. Moreover, the reflection from the leading edge of each surface feature becomes an over-exposed specular highlight, while the trailing edge is cast into shadow. The resulting image is harsh in contrast and the gradients are strongly directional, and fine surface texture may be exaggerated.

In summary, to produce a good photography of a silver coin, mostly of shallow relief and often specular in appearance, careful attention needs to be paid to incident angle of the lighting. A setup with two lights can produce a good rendering and surface relief. Instructions for coin photography are described in Goodman [6] and Hoberman [7]. Digital photography with or without a reproduction table, or even the use of flatbed scanners for reproducible lighting, ${ }^{1}$ is used today to produce $2 \mathrm{D}$ digital images for searchable coin databases alongside textual information.

\section{Dome photography for PTM/RTI visualisation}

The re-lighting method PTM (Polynomial Texture Mapping) was first developed by Hewlett Packard Research Laboratories [8] and immediately identified as a potential tool for cultural heritage imaging. PTM is a special case of Reflectance Transformation Imaging (RTI), a family of computational photography techniques that capture a subject's surface shape and colour and enable the interactive re-lighting of the subject from any light direction seen from one top-down point of view (see Fig. 3, demonstration or PTM/RTI software in, Additional file 3: Film S3). RTI methods do not record the 3D surface directly but rather estimate the angular reflectance distribution

\footnotetext{
${ }^{1}$ Personal Communication from the $\mathrm{COSCH}$ Roman Case study meeting on 22 June 2016 at University College London. Participants, see Acknowledgements.
} 

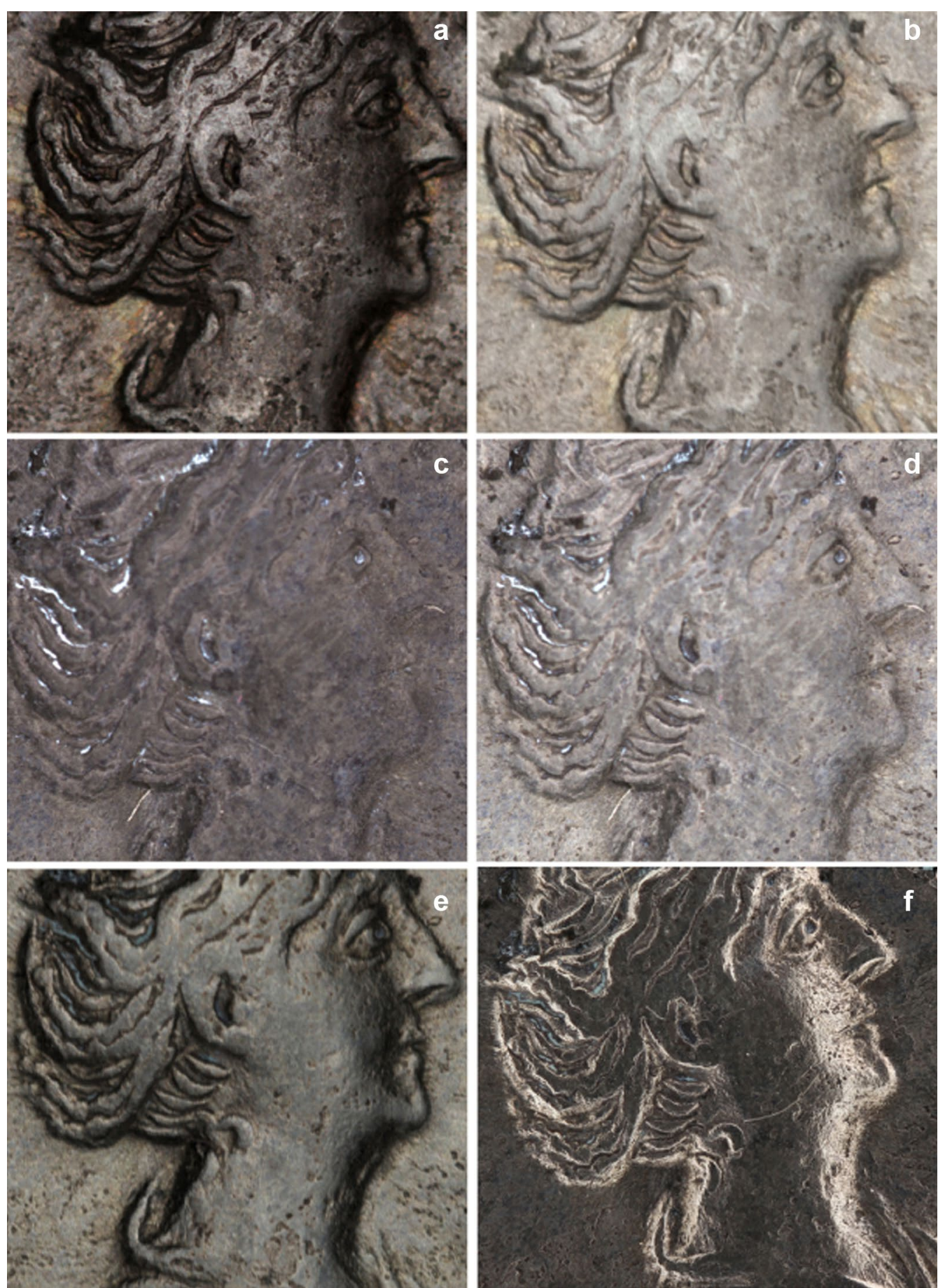

Fig. 3 Coin A, obverse (detail) of six different image dome captures (PTM/RTI) a RTI capture UCL dome; b RTI capture CyI dome; c RTI capture RBINS Minidome, albedo mode; d RTI capture RBINS Minidome, ambient mode; e RTI capture with dome at Southampton university; ff for comparison of detail: a focus stacked picture (Aurore Mathys, RBINS)

at each point on the surface and hence create the illusion of $3 \mathrm{D}$ viewing of artefacts. Both technologies allow the application of imaging filters to enhance the viewing for researchers and visitors [9] as well as inspection of surface details and manufacture [10]. Recording in the dome enables reproducible lighting and therefore a controlled environment. This can potentially be used for the monitoring of colour and surface changes. 
For this study, six different imaging domes were used on the test coins. The comparison of these technologies was challenging due to the following variables: different equipment (dome, lens, camera, and lighting), different orientation of the coin, proprietary output formats, variety of software to create RTI and viewers. Visual comparison and statistical methods were used to assess colour realism, specularity, impression of the dimensions, sharpness of rendering and appearance of the surface topology [11].

\section{Focus stacking}

Even though coins are of shallow relief, the use of focusstacking can significantly improve the detail and readability of the rather small coins at high magnification, as shown in an example for test coin A, see Fig. 4.

The low cost focus stacking setup used to produce this image was composed of a closet with two diffuse flashlights positioned under the object. Pictures were taken with a Canon EOS 600D DSLR placed on a Cognisys Stackshot, which was mounted vertically above the object. Several pictures at different focus distances were taken for each view to be processed afterwards in a stacker software in order to achieve an extended focus picture [12].

Focus stacking can also be achieved through digital microscopy. The images are known of having a high standard deviation of set of pixels in the vicinity of the pixel in focus. The stacker software utilizes this rule and examines for every pixel of the image the whole stack of identically located pixels and selects the image of the highest deviation value and from this image it copies the examined pixel and its neighbours into the final image of enhanced focal depth [13].
Focus-stacking may also be accomplished by a digital microscope with robotic stage. The illumination is an adjustable combination of axial and indirect (black field) light. The focus stacking and stitching are performed on part of the coin surface. Focus-stacking leads to high photographic detail for a 3D surface model and for remote inspection or inspection next to the coin, see Fig. 5.

\section{Photogrammetry and structure from motion (SfM)}

Digital close range photogrammetry, using a DSLR camera and lighting, is an established non-contact optical technique from remote sensing and is used for the documentation of objects by aerial photogrammetry at a variety of scales, amongst them museum artefacts and heritage buildings. Photogrammetry is capable of delivering high-resolution colour images ideal for the documentation of current condition and damages on the surface of the artefact, enabling the visualisation of details of the order of $50 \mu \mathrm{m}$. Structure from Motion (SfM) uses the principle that movement through a scene allows an understanding of the shape of the scene in three dimensions, in the same way as walking through a room allows one to visualise the space and objects placed within it. In $\mathrm{SfM}$, this is represented by a series of systematic viewpoints; overlapping photographs are taken from multiple angles around the object, either by moving around the artefact, or by moving the object on a turntable in front of a camera on a tripod. The result will be of higher quality if there is no directional lighting that produces shadows, for example if photographs are taken with indirect lighting to the ceiling or using a light tent acting as a diffuser with lights. The digital output is a $3 \mathrm{D}$ coloured point cloud, i.e. a large number of co-ordinate points in

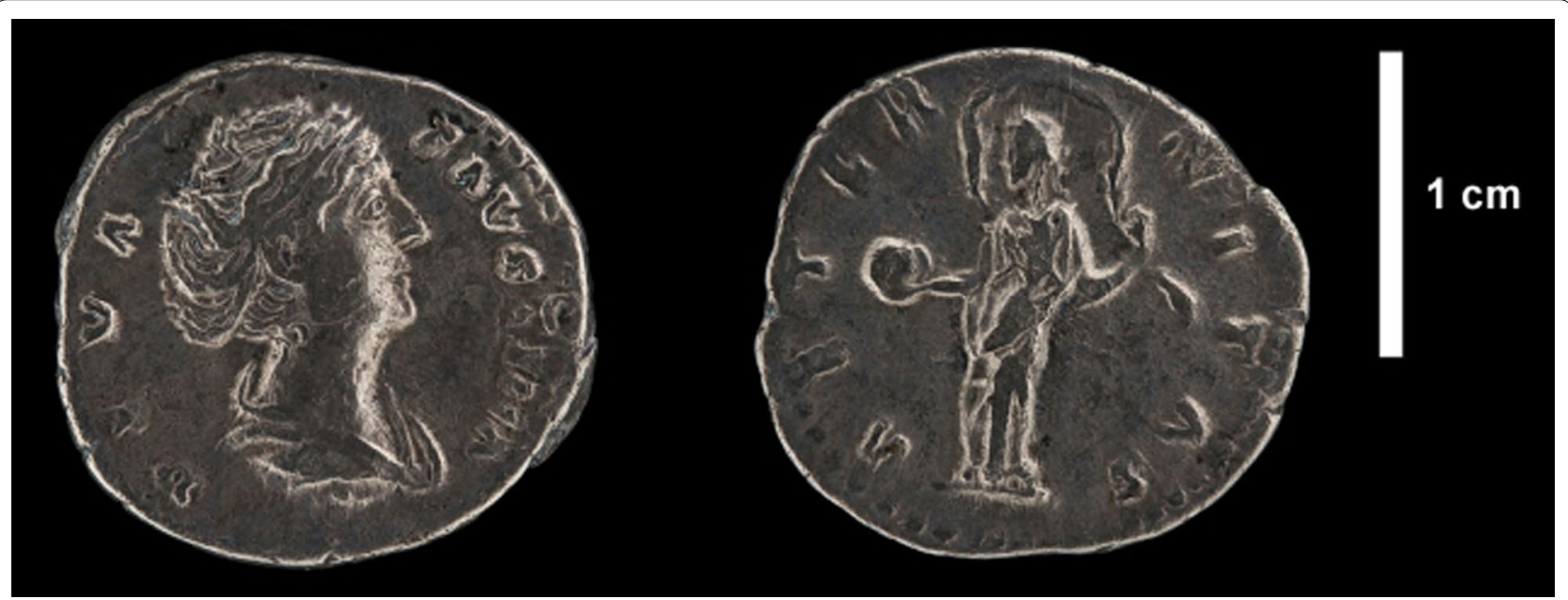

Fig. 4 Coin A obverse and reverse, image obtained from focus stacking picture (Aurore Mathys, RBINS) 


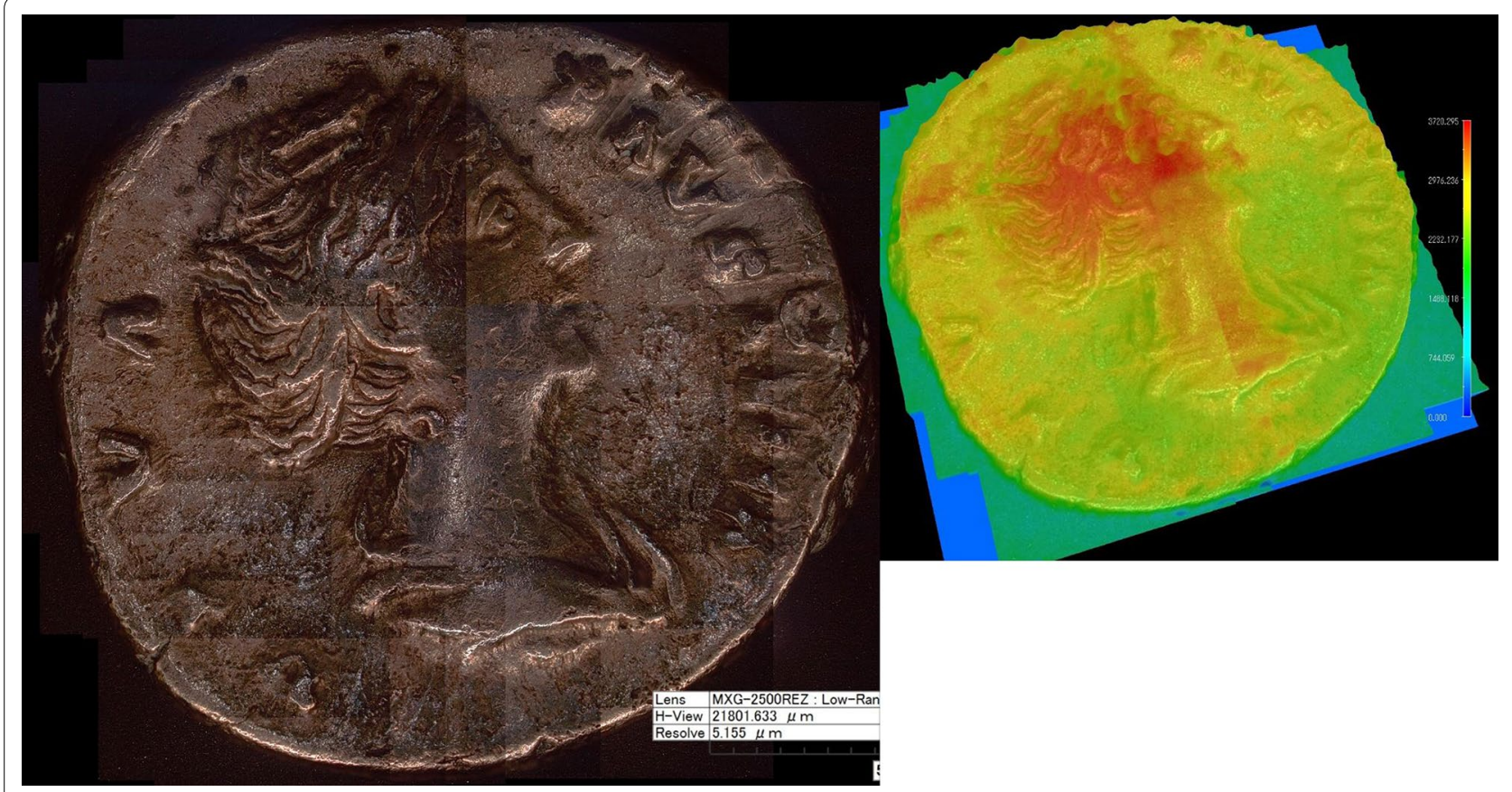

Fig. 5 Coin A obverse, digital microscopy (Jaroslav Valach, ITAM)

space, or a surface model, i.e. coloured polygon mesh of triangles, [14] and [15]. In summary, photogrammetry and SfM are applicable for objects of variable scale and surface properties [16] and therefore also applicable to the small Roman coins of this study.

For the surface inspection of coins this provides an interactive digital display where the coin can be magnified and turned around to inspect surface accretions as well as writing. Applied filters in software can enhance the viewing (see demonstration in Additional file 2: Film S2).

\section{D laser and structured light scanning for 3D spatial capture}

For small and medium size objects, 3D laser scanners and 3D structured light scanners are often used for topometric data acquisition. Both systems are based on the triangulation principle. The coins pose two challenges to 3D scanning systems: surface resolution on a small and nearflat surface, and material specularity, i.e. shininess. The ideal object properties for the selected 3D scanner have features no smaller than its Ground Sampling Distance (GSD) or finest resolution (the distance to resolve the finest detail on the surface). If a scanner can record a resolution of $50 \mu \mathrm{m}$ for example, the smallest recordable and identifiable feature on the dataset will not be smaller than $100 \mu \mathrm{m}$. A human with acute perception would expect to see more from a close up inspection with a hand-lens, than from a 3D scan at $100 \mu \mathrm{m}$ sampling distance.
For both, photogrammetry and 3D scanning, the ideal object surface would also be a matte (i.e. diffusely reflecting) surface. For the surface recording of an object like the Roman coins the challenge of a specular or shiny surface needs to be overcome, due to the glare into the optics. A strategy to record from an angular position from object to sensor might help the recording process. The difference between the points recorded on the surface from a nadir (or top down) position versus an angular recording can be seen in Fig. 6. Occlusions and transparencies can also be challenging for 3D scanners and photogrammetry, but these are not applicable here. Recording of the thin object from the side, as well as the alignment of back and front also poses a problem with coin-like objects.

In laser scanners employing the triangulation principle, the triangle is formed between the sensor with (1) an emitter/laser line projection with known angle of the emitted laser line and (2) an offset optical sensor with a known baseline, i.e. distance to the emitter and (3) the surface point where the laser line hits the object. This setup allows the measurement of adjacent points in a specific depth of field of the triangle commensurate with the sensor specifications [14]. Detailed information about the 3D laser scanners used in this study can be found in Table 1. Visual outcomes of the three different laser scanners used in this study can be seen in Figs. 6, 7 and 8. 


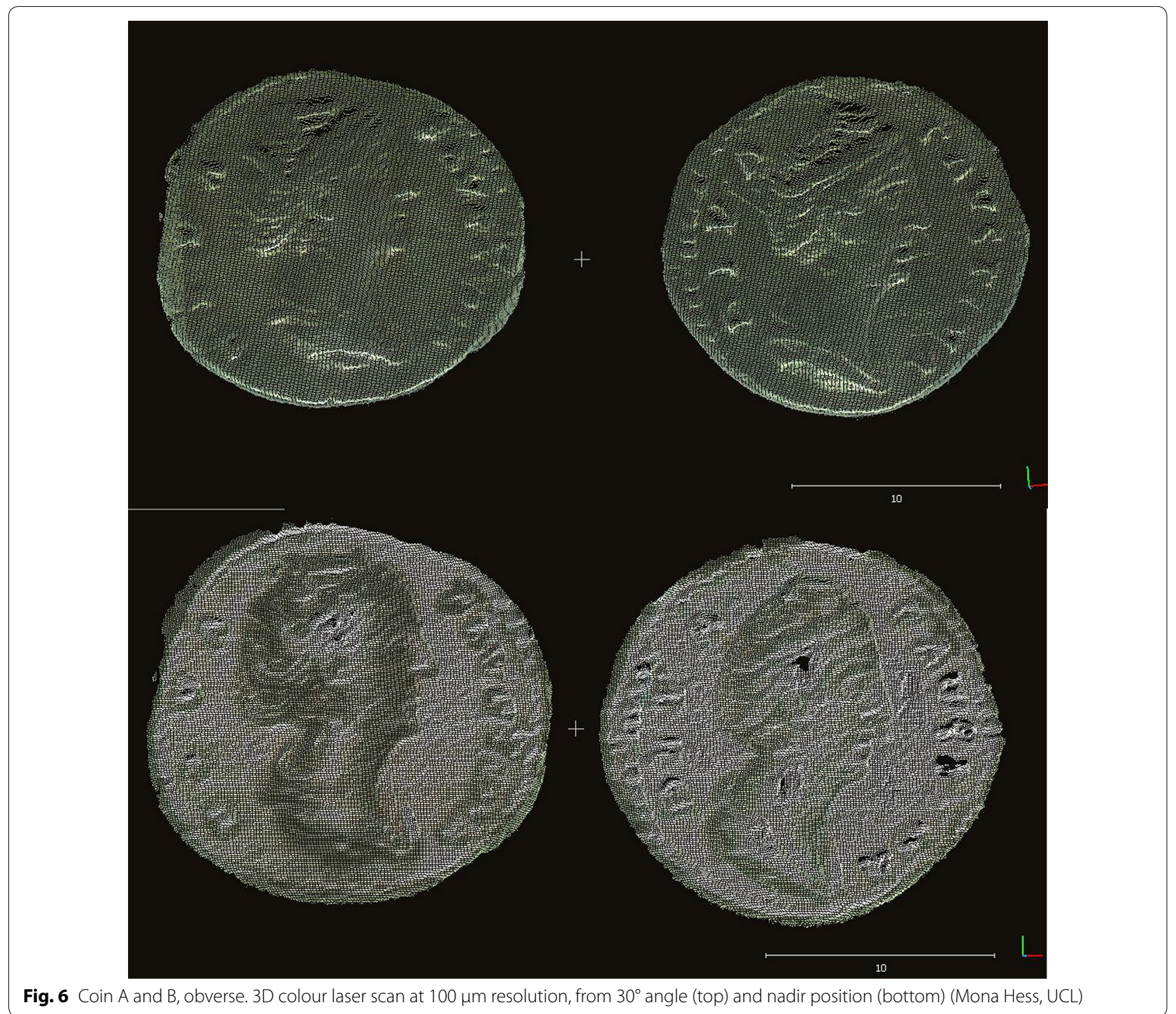

A structured light scanner is an area-based imaging technique, consisting of a projector and at least one camera. Instead of projecting laser lines or spots, it projects patterns of a structured light sequence (called Gray Code or Phase Shift sequence) for topometric data acquisition. The calculation of 3D data is based on the triangulation principle; typical triangulation angles are at approximately $30^{\circ}$. The camera is mounted in a calibrated position relative to the projector, and thus defines the base line of emitting system and measurement sensor. The scanning system projects light patterns onto the object surface. The contrast of the light patterns influences the quality of scan results (Fig. 9, [17]).

An advantage of many close-range 3D systems is that the kit can easily be transported to the site or museum.
Some are also flexible: various fields of views can be recorded with a single sensor through changing elements, either camera lenses or by varying the baseline, i.e. the distance between the projector(s) and camera. A further advantage is the speed of recording for one $3 \mathrm{D}$ record, the projection of all patterns lasts only a few seconds. While structured light sensors are limited by pixel count, data density and range resolution, they usually deliver sub-millimetre sampling of the surface [18], some even capable of reaching resolutions in the order of $20 \mu \mathrm{m}(\mathrm{XY})$ and $3 \mu \mathrm{m}(\mathrm{Z})$.

See Fig. 7 for a 3D image by structured light of Coin B, where colour information could be mapped from an sensor-internal calibrated camera or external camera using add-on software. 


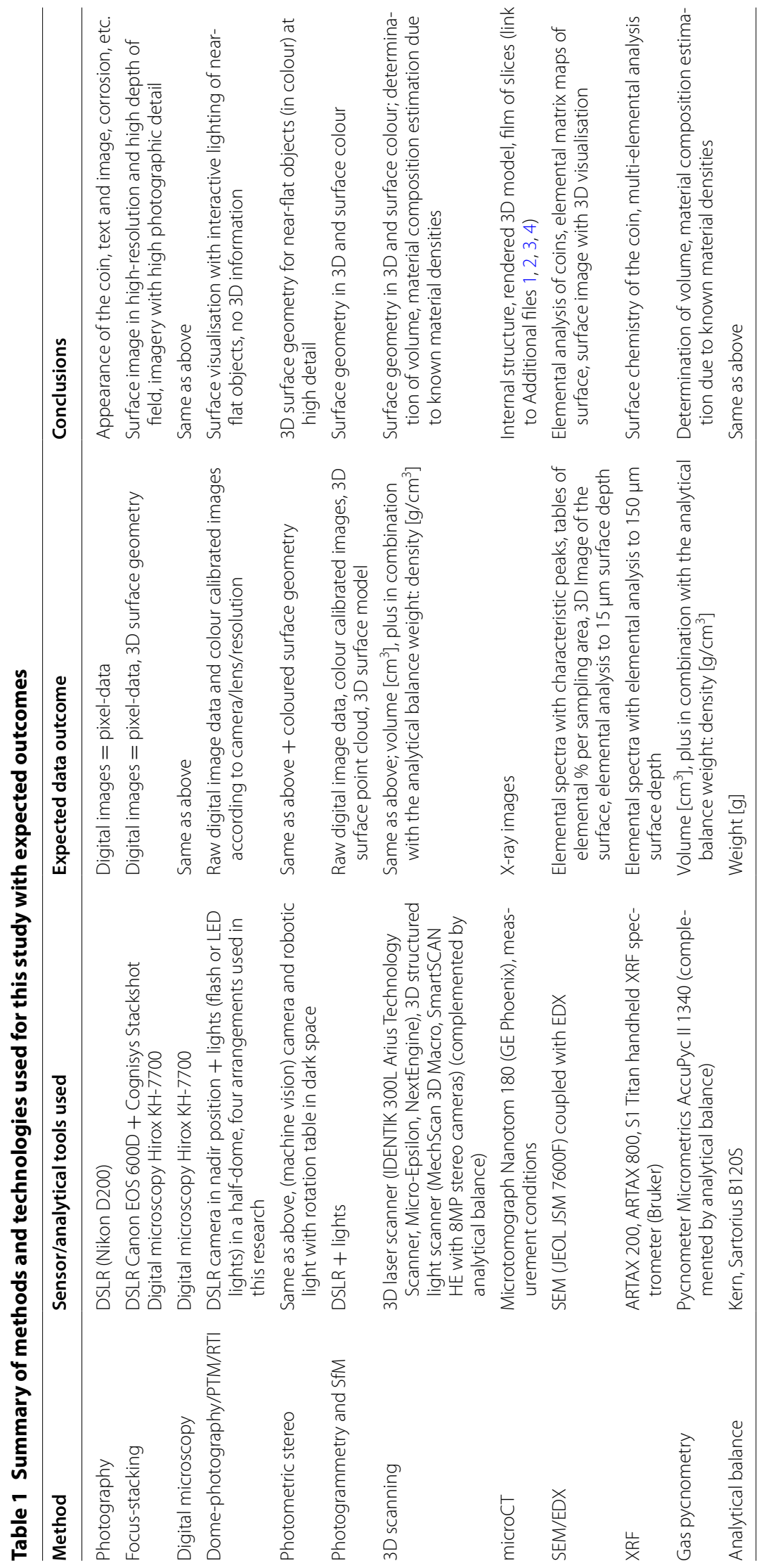



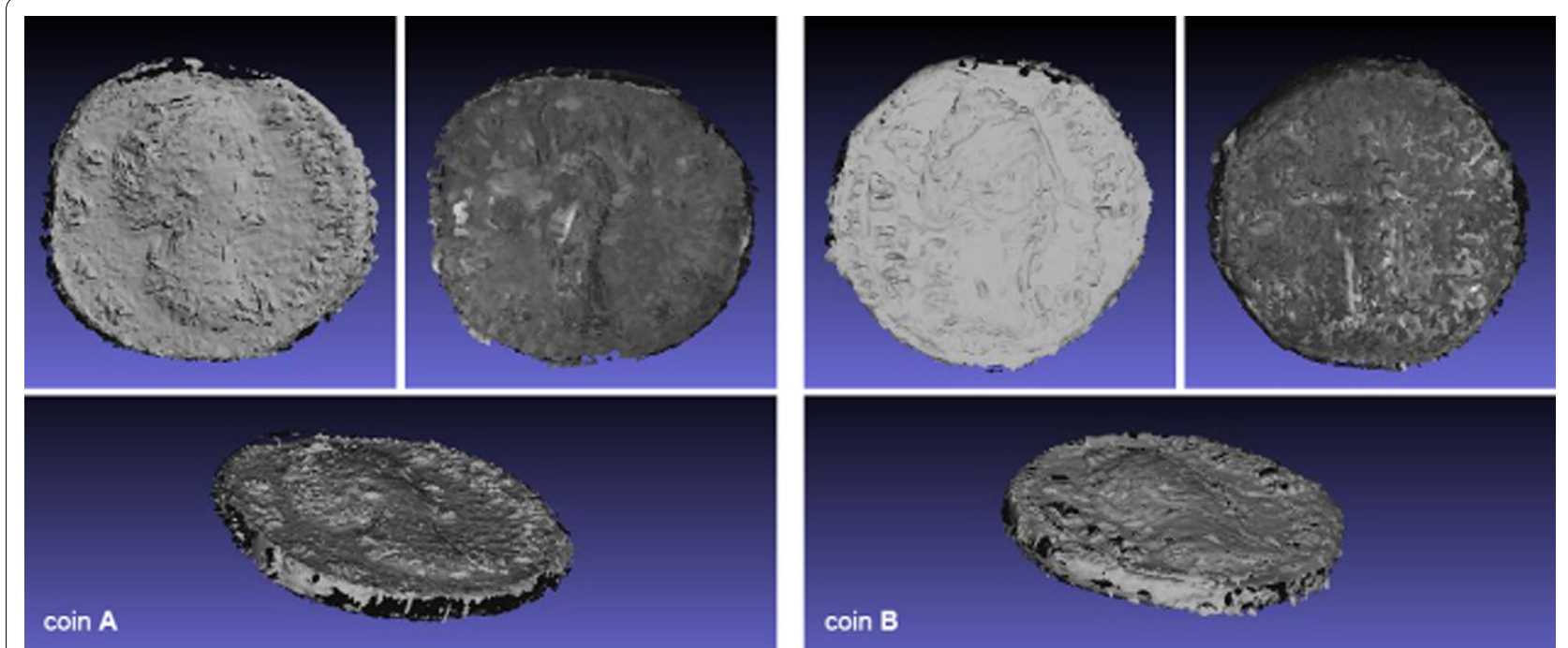

Fig. 7 3D laser scan of, coin A and B with NextEngine HD (Vera Moitinho de Almeida)

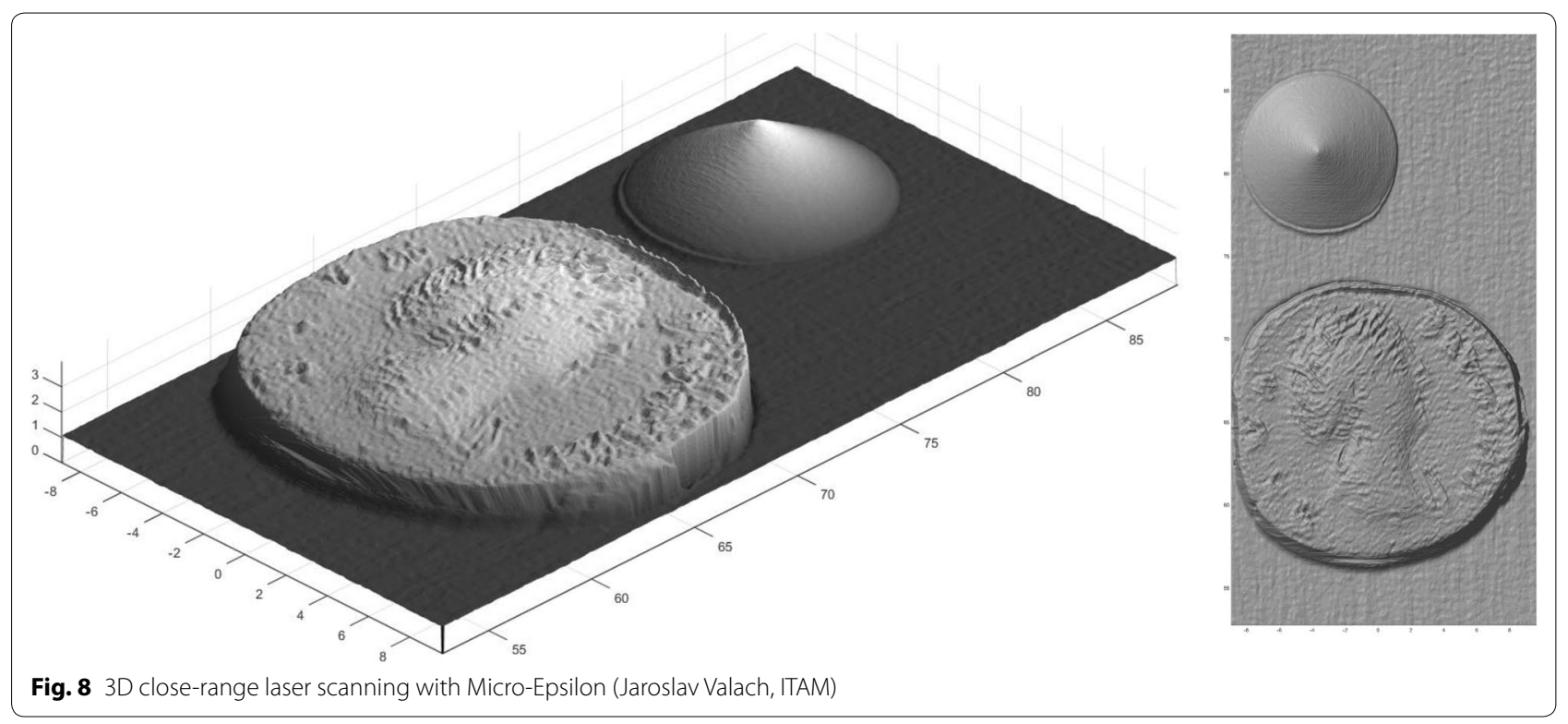

\section{Photometric stereo}

The 3D surface geometry, defined by the array of surface normal vectors, may be deduced from radiometric measurement of reflected light if the illumination geometry is known. This method enables the documentation of topography and visual appearance at the same time.

For this study, two setups were used:

In the first setup two representations, PTM dome images and 3D colour laser scanning were combined to produce a digital elevation map of each coin with the accuracy of the scanner and the fine detail of the photography. The result was a realistic rendering of the coins at a spatial resolution of 75 pixels $/ \mathrm{mm}(13 \mu \mathrm{m})$, in which the fine detail modulated the underlying geometric form of the surface relief. Results are shown in Figs. 10 and 11 (a detailed description of the method is available in [11].)

Secondly, a setup with a fixed machine-vision camera and illumination and a robotic arm to move the object in a light-controlled dark space. The resulting resolution is about $50 \mu \mathrm{m}$ (see Fig. 12).

Both methods produce very high-resolution surface 3D point clouds and allow surface measurement from the computed profile. These representations are very similar to the inspection of a coin with a magnification lens, but 


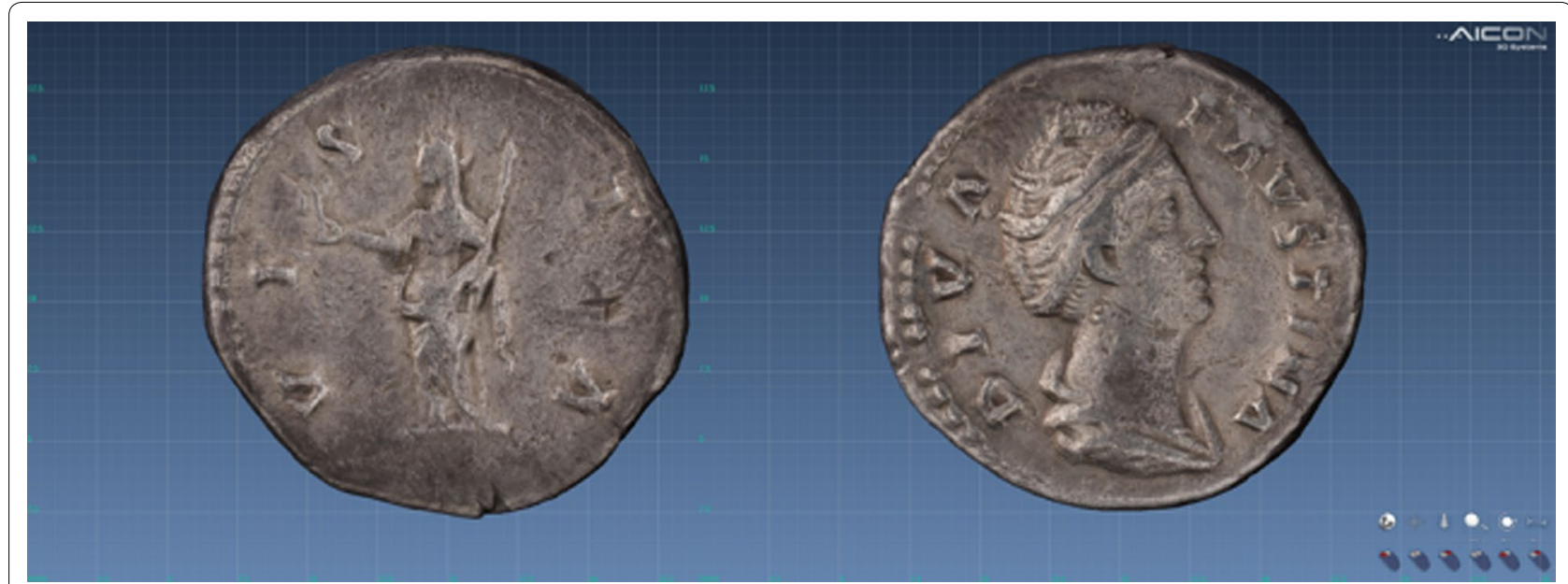

Fig. 9 3D structured light scan of Coin B, reverse and obverse. Colour information mapped from an external camera (Dirk Rieke-Zapp, Aicon 3D Systems)

can be presented on a larger screen (see demonstration of 3D surface model in, Additional file 1: Film S1).

\section{Quantitative geometric comparison of 3D surface models}

Rigorous procedures are important for the documentation, characterization, and understanding of each individual 3D model of a coin. A quantitative topological and geometrical comparison of 3D surface models was carried out using the following indicators: 3D vertices/ triangles, maximum diameter, shape factor, surface area, volume, along with measured weight and density of the coins $(C, D)$. Furthermore, comparisons between the 3D models were undertaken looking at the convergence and RMS error of the alignment, and deviation values (standard, mean, upper and lower deviation). Figure 13 shows pairwise differences between complete 3D models of coin A: colour difference map, distribution of differences, and standard deviation. It was found that multiple factorssuch as sensor limitations, used methods and techniques to acquire, process and analyse 3D data-influenced the numerical outcomes and therefore the confidence for the characterisation and study of the coins. Notwithstanding, the imaging technologies proved to be a valuable tool for the documentation, study and dissemination, as well as for the improvement and automation of the analysis of coins [3].

\section{Physico-chemical analysis of coins}

The use of physico-chemical analyses is applicable to the study of coins, amongst others to assist in material composition. For this study, a series of surface sensitive analytical methods have been used, and as the coins are portable, they could be brought to participating institutions.

\section{$X$-ray computed microtomography}

$\mathrm{X}$-ray microtomography method (also called X-ray microCT) is an imaging method allowing the $3 \mathrm{D}$ reconstruction of an opaque object by illuminating it with $\mathrm{X}$-rays in different directions by transforming a directionally dense set of object's $\mathrm{x}$-ray radiograms into complete 3D model [19]. It can be used for the visualisation of internal microstructure of 3D objects. This method helped identify cracks and impurities through the coins and voids inside the coins, and allowed visualisation of defects and corrosion effects. Results show a heterogeneous X-ray absorption in different parts of the coin, and this could be due to possible enrichment of elements and wear on the surface, or molten metal which had a heterogeneous distribution of elements. Figure 14 shows three perpendicular microCT sections and the rendered 3D model visualises a crack inside the Roman coin A. The 186 resulting images of horizontal slices through the coin can also be viewed as a film sequence (see a demonstration in Additional file 4: Film S4).

\section{Scanning Electron Microscopy (SEM)/Energy-Dispersive X-ray Spectroscopy (EDX)/EMPA (Electron Microprobe Analysis)}

In Scanning Electron Microscopy, the electron beam gradually passes in rows across the area under investigation, and at each point on these rows it causes physical interactions with the surface whose intensity is recorded by the probe, and converted to the grey scale of the image being formed. In this way, images with magnification, 


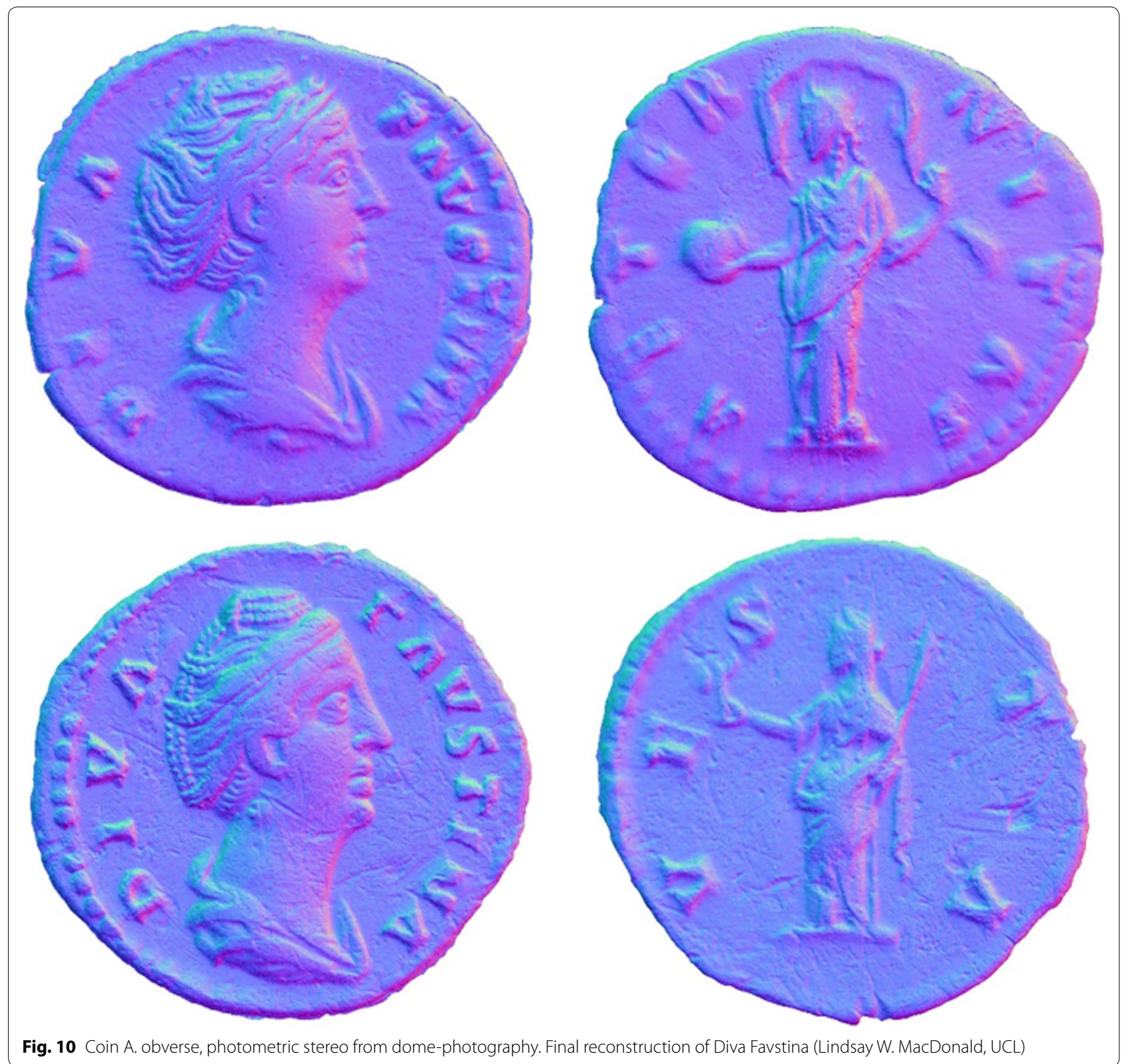

depth of field, and information that cannot be reached by light microscopy, can be obtained. The energy of the incident electrons is sufficient to trigger X-ray fluorescenceexcite the electrons in the surface atoms, and they emit their characteristic spectrum upon return to the basic state. By analysing the spectra, it is possible to determine the species of atoms composing the surface, but also their relative weight proportions. Composition of surface can be studied in individual points or in the whole area forming "composition maps", see Fig. 19. It therefore offers simultaneous morphological and compositional surface analysis, as well as visualisation of a surface to a depth of typically 1-5 $\mu \mathrm{m}$. Material samples often are cut, embedded in resin, and polished for the sampling, but this was of course not performed on the ancient Roman coins and is avoided when examining artefacts. Whilst SEM yields surface specific local information of spectra, it does not give an overall value of the material at the inside of the coin due. If homogeneity is assumed it needs to be stated, and the results are of course not transferable to the material composition inside a coin when measuring plated coins. SEM also has limitations to yield results about the underlying material if corrosion or other dirt covers the surfaces. 


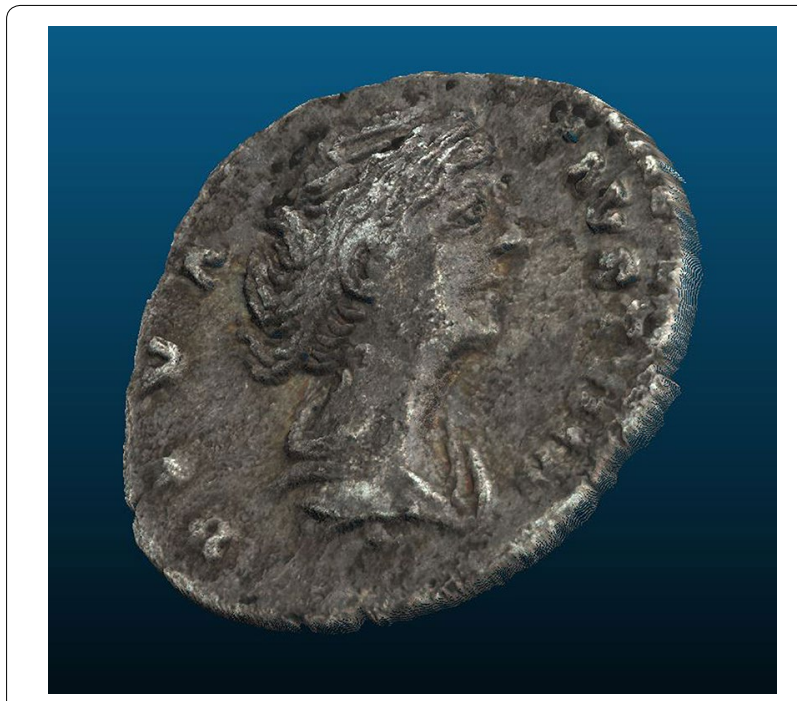

Fig. 11 Surface normals from photometric image sets (Lindsay W. MacDonald, UCL)

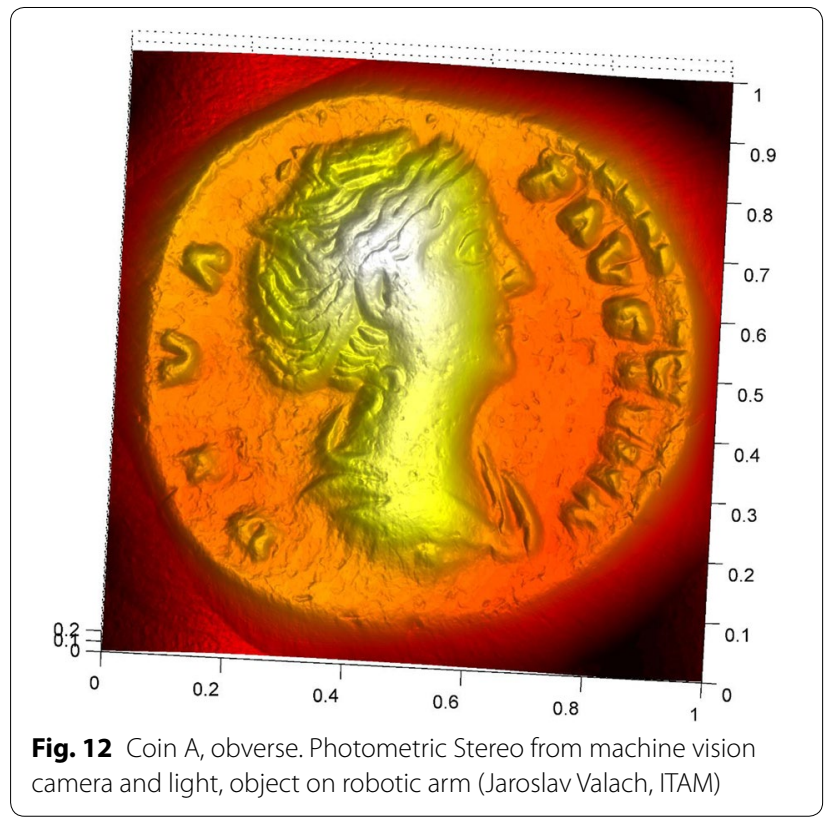

EDX or EDS (Energy-Dispersive X-ray Spectroscopy) is an analytical method used for elemental analysis of a sample under test, in this case silver coins. Usually, the EDX device is part of the SEM (scanning electron microscope). In this study, EDX was used for the elemental analysis of coins, determination of silver content and trace metals, for addressing the issue of authenticity of the coins. The method is known for its sensitivity to surface treatment of examined object and the reliability of composition quantification decreases with a presence of light elements. For precise determination of surface composition WDS (wave dispersive X-ray spectroscopy) should be used [20]. Examples for the measurements on coins are shown in Figs. 15 and 16.

Atomic composition was determined at six rectangular areas for both coin A and coin B. Because of high spatial resolution, differences in results can be attributed not only to measurement error, but also to true local variations of composition of the coins. The average values (96.9\% of silver for coin A and $92.56 \%$ for coin B) can only cautiously be used to deduce the silver content in the whole volume of coins. Standard deviations indicate variability of results -0.603 for coin A and 1.879 for coin B).

EDS analysis was performed also on another SEM to assess a difference in results. The analysis can be carried out point-wise as is shown in Fig. 15, the above mentioned spatial variation of composition is best illustrated by Fig. 19 showing concentration maps for selected elements. Figure 17 is presenting the composition measurement at three different spots of coin B (SEM of Coin B); it indicates differences between results produced by different devices when compared to Fig. 16.

EMPA for coin A is illustrated in Figs. 18 and 19. It should be noted that some places on coin are dirty and the fact can alter the analysis, as the electron beam penetrates few microns of material.

\section{Micro X-ray fluorescence (XRF) spectrometry mapping}

This case study also explored the use of the non-destructive analytical technique, X-ray fluorescence (XRF) spectrometry, which has become a favoured analytical method in numismatics. The XRF method differs from SEM/EDX by providing depth information up to $150 \mu \mathrm{m}$. A very accurate $3 \mathrm{D}$ representation of a coin may be combined with chemical maps resulting from XRF measurements. Previous research on this topic was undertaken by Del Hoyo-Meléndez with relevance to elemental surface analysis of medieval coins by XRF [21]. The method shows potential for providing insights into the provenance of the raw material and manufacturing processes. The results can also be mapped to the surface to visualise the concentrations of specific elements.

For this project, three different XRF spectrometers, one of them portable, were used to compare the results of the elemental composition of the surface. With each of the three instruments, multiple measurements were taken from distinct spots and averaged to obtain an uncertainty value of the measurement. Whilst a detailed description of the thorough and scientific measurement method has been provided by the expert, it will not be presented here. It can be summarized that chemical composition of coins was determined by three different methods-handheld 


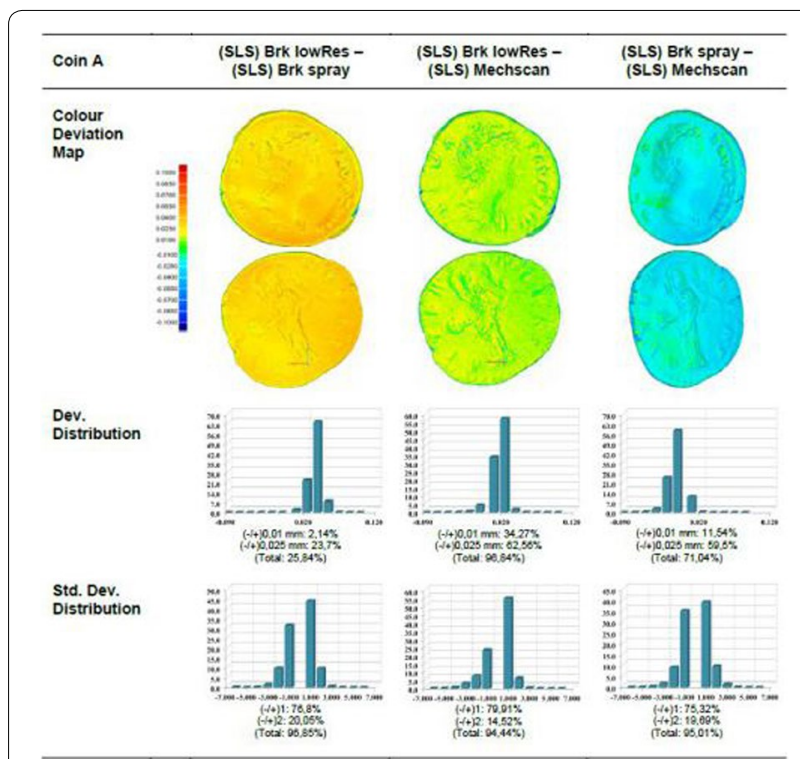

Fig. 13 Pairwise differences between complete 3D models of coin A: colour difference map, distribution of differences, and std. deviation (Vera Moitinho de Almeida 2016_Reference [3])

$\mathrm{X}$-ray fluorescence (S1-Titan, $5 \mathrm{~mm}$ analysis spot), micro X-ray fluorescence (ARTAX 200, qualitative and quantitative data, chemical compositions maps) and by energy dispersive spectroscopy in SEM, respectively. Due to the different nature of the devices including standard deviation values and the positioning of the coins (ARTAX on a horizontal position with a support, and the handheld devices measuring surface contacting the coin) certainly identical measuring points could not be investigated and the investigated areas differ. To concentrate on the silver content, the methods yielded coin A 93.0\% (relative error For Ag \pm 2.0 , S1-Titan), 96.0\% ( \pm 0.75, ARTAX 200) and 96.9\% (SEM/EDX) respectively, and the silver content of the coin B 95.1\% (relative error for Ag \pm 2.0, S1-Titan), 97.9\% ( \pm 0.75, ARTAX 200) and 92.5\% (SEM/EDX) respectively. Although the penetration of the SEM/EDX device is lower $(80 \mu \mathrm{m})$ with respect to XRF $(150 \mu \mathrm{m})$, it can be observed that the results are generally in agreement. However, it is worth noticing that the Ag concentration for coin B is lower in the SEM/EDX analysis as an outlier. The copper content was estimated to ca $4 \%$ and the other elements are mostly dirt from handling - carbon and oxides based compounds. The results show that multi-elemental analysis can be obtained, which for this project help complement other measurement methods (more information in [3] and [22]).

\section{Gas pycnometry}

The weighting of the coins was undertaken using pycnometry, which is a non-destructive and non-invasive method during which the coins are only exposed to helium gas in a vacuum. This allowed a determination of the coin density for an estimation of the alloy composition. The results allow the calculation of the compositions if an assumption is taken that the binary alloy is valid. The method works best when the tested specimens fills the measured cavity, when coins are flat and of low volume. The interesting outcome of the measurement of the coin density was that because of the flatness of the coin, the physical method was stretched to its limit and did not reach optimal precision in determining the actual volume of the coin as well as estimation of its composition. Therefore, in this particular case the optical methods for digitizing the coin and calculating its volume delivered better results.

Summary of methods and technologies used for this study Table 1 provides a summary of methods and technologies used for this study. A further detailed overview of the technologies can be consulted in book chapter [3] and [22].

\section{Discussion of results}

The aim of this study was to demonstrate a multi-modal and interdisciplinary approach to analysing and interpreting coins beyond the applications currently used in museums and numismatic collections. A number of technologies were applied to examine two selected Roman Coins to glean more information about their authenticity, materials, manufacture, and iconography. Through consultation with expert numismatists, typical tasks in numismatic collections were summarised above in "Background". These tasks were then addressed by a combination of optical imaging and other analytical methods, such as physico-chemical. Tasks towards the physical conservation of the coins (Tasks a, $g, h$ ) are supported by optical imaging (Tasks b, c, d, f, g, i), with additional evidence by physico-chemical analyses (Tasks c-corrosion products, e, f, g, i). A combination of different optical and other analytical methods from conservation science has been found useful to obtain a holistic information of the surface properties, geometry, and colour as well as material properties and internal structure of the two exemplary Roman Coins.

Discussion of optical imaging methods used in this case study The use of optical imaging methods has produced the following conclusions, which are transferable to research on small cultural heritage artefacts in general:

- Optical recording technologies in 2D and 3D have matured in the last years, but research and development in hardware and software is still ongoing [23, 24]. Particularly, there is a challenge for standardiza- 


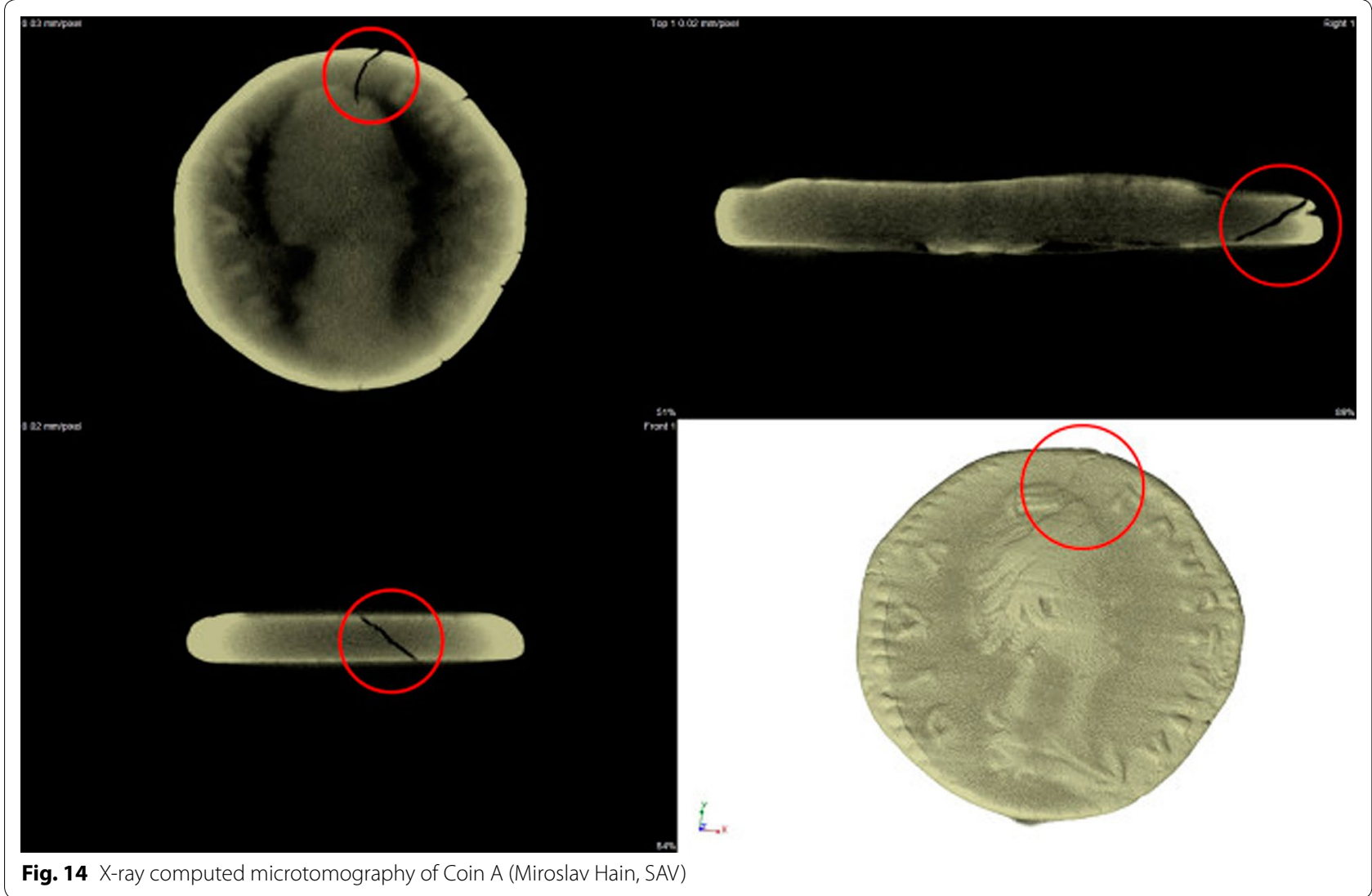

tion of recording decision-making processes for the recording and documentation of digital data. The London Charter has provided some first proposals $[25,26]$. Further challenges are policies and strategies for long-term digital preservation, as well as for transparency and access to digital data [27, 28]. All digital data and corresponding metadata (data information that provides information about other data) and paradata (information on how the capture did take place: for example type and model of machine, calibration, parameters, place and time, environmental conditions, operator decisions during recording and processing) produced were shared during this case study and have been saved in a specific repository and are made available on a project website.

- Depending on the characteristics of the object, the scale of observation and the type of information required, the accuracy, resolution and precision of the measurements should be selected high enough to fulfil the numismatist's or experts' needs for scientific documentation and study.

- A comparative and critical assessment of existing methodologies for PTM/RTI dome acquisition for the high-resolution visualisation of the coin surfaces showed that currently the quality of the results is dependent on the capabilities of the operator in combination with hardware and software parameters. Furthermore, there are currently no standards for the paradata or metadata to describe this process [3].

- Photometric stereo produces a highly resolved surface. Despite the fact that the 3D surface models from 3D scans and SfM did not reach the highest quality of the 3D data acquired by structured light scanners, the photometric imaging should be considered as an additional and alternative method for producing 3D models for dissemination purposes [11].

- A methodological framework (Fig. 2) has been proposed for the 3D digital data acquisition, process and analysis of historical coins [3]. It has taken into account the order and type of other methods used, as well as the topological and geometrical characterisation and comparison of 3D models, with the particular example of coins. The workflow starts with the research question centred on a cultural heritage object, which influences the next steps of planning, data collection, data analysis, and interpretation of results, which then feed back into answering the original research question. Data collection is at the heart of this workflow and is informed by the results of using non-invasive and invasive technolo- 


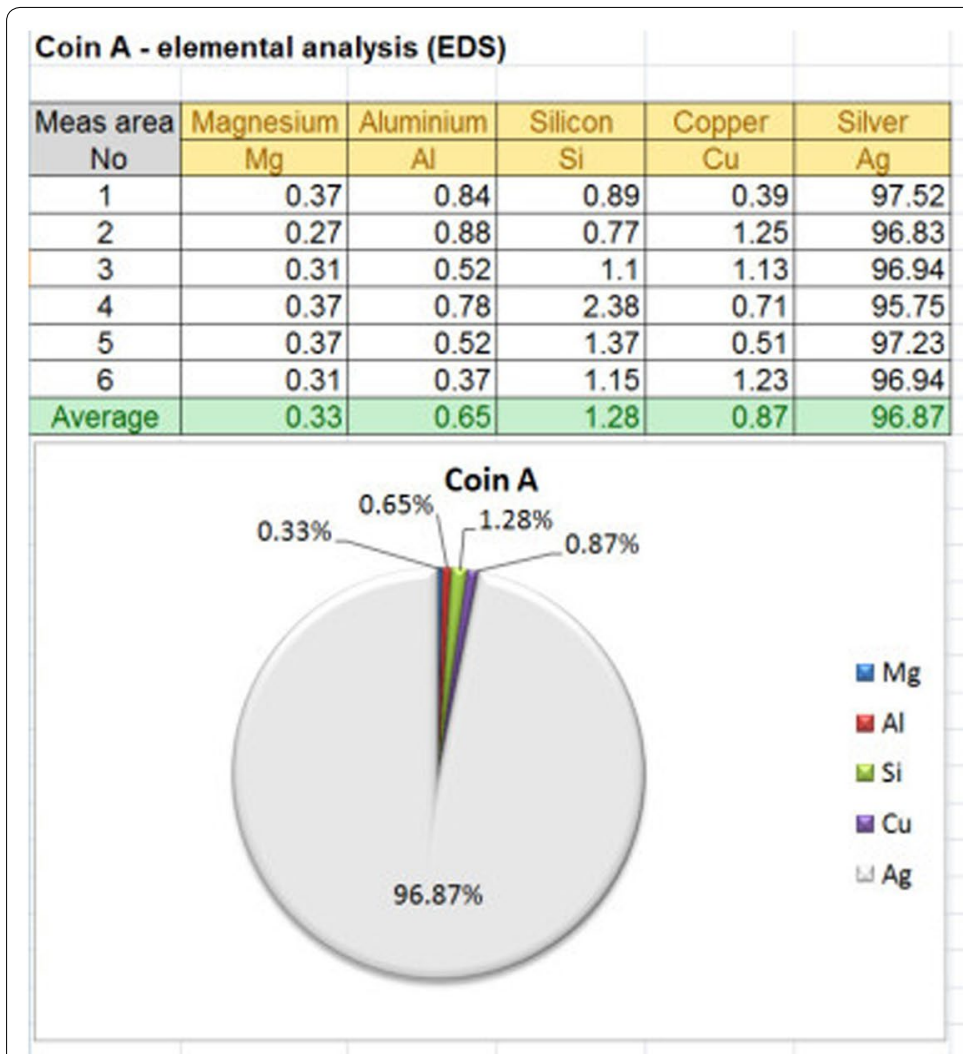

results in weight $\%$

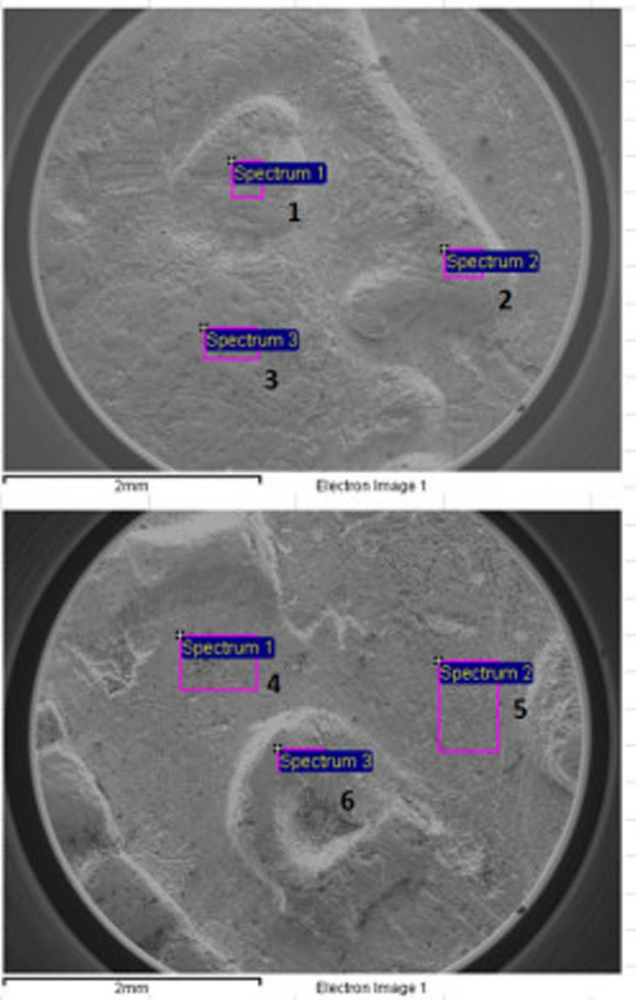

Fig. 15 EDX elemental analysis of Coin A (Miroslav Hain, SAV)

gies, which again is governed by an agreed $3 \mathrm{D}$ data strategy noting all parameters of environment, hardware, software, technicians and the cultural heritage object itself. The importance lies in the recording of all metadata and paradata about the process towards a scientific and technical documentation. This proposed framework could be transferred to other types of objects. Further details of data collection of this project are listed in detail in another publication [3].

- Technologies used to produce 3D digital datasets applied here on Roman coins allow non-destructive, non-invasive recording of the surface to construct a virtual image of the real object that can be navigated and explored on the display of a computer or even mobile device and in Virtual Reality. With developments in 3D scanning technologies over the past 10 years, it is now feasible to digitize the objects of heritage institutions and to create 3D archives, thereby enabling visualization of each object in the round. Nevertheless, many practical issues remain concerning the precision of the system, accuracy, and resolution of the datasets, speed of acquisition and time required for post-processing.
- Consultation with cultural heritage professionals has confirmed the relevance of 3D imaging and established that, by creating accurate geometric representations, user motivations can be addressed for surface measurement and inspection, deformation monitoring, and 3D printing with particular benefits for conservation and research, [29, 30].

Discussion of Physico-chemical analytical methods used in this case study A crosscheck between all results of SEM/EDX and XRF shows similar results of chemical characterization, with difference of the depth of material penetration of each method. In the case of the Roman coins, curators have some interest in the composition, especially percentage silver (\%Ag). In this study, upon hearing the similarity of results across different physicochemical measurements named above, numismatists were dubious about our measurements of $97 \%$ silver (Ag) in Favstina coins, which post-date Nero's debasement. One expert summarised that the production of silver coins was as refined as possible during Nero's reign until $70 \mathrm{AD}$ with a high \% Ag, after which it dropped to below 90\% Ag, and from 190 AD onwards dropped dramatically 


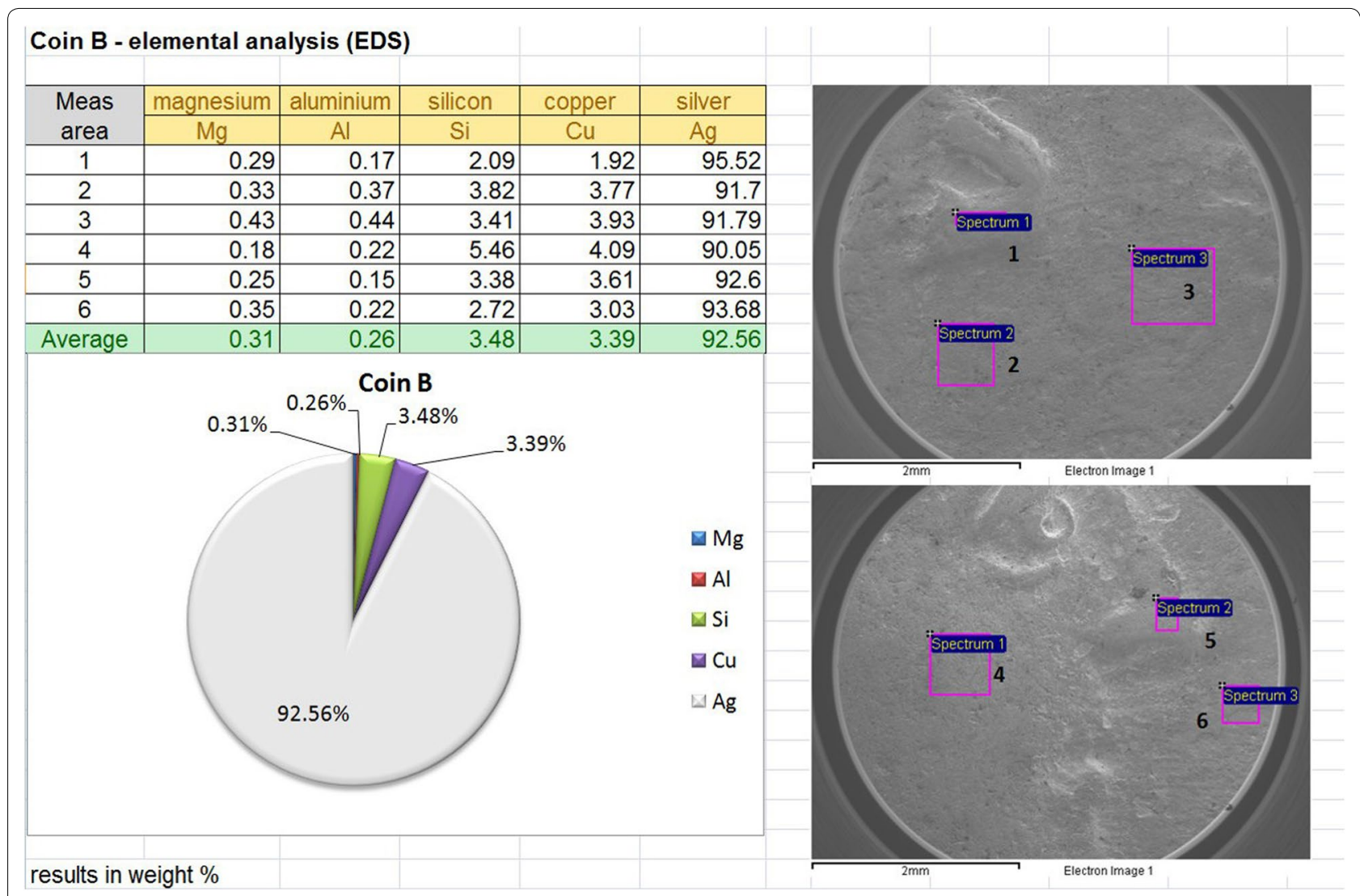

Fig. 16 EDX elemental analysis of Coin B (Miroslav Hain, SAV)

to ca $50 \% \mathrm{Ag}^{2}$ On this basis, the authenticity of the coins, which are believed to be a posthumous deification issue from 141AD, should be re-examined.

Discussion of interdisciplinary approach and framework used in this study This project featured an interdisciplinary approach in consultation with numismatic experts. The project team was formed of twelve specialists, some with expertise in two or more disciplines, including: archaeology, art history and museology, conservation and heritage science, chemistry and electrochemistry, mechatronics and engineering, metrology, computer science, computer graphics and data processing. This joint panel of experts produced holistic knowledge about two ancient Roman coins, with a great expenditure of time and care with the aim to produce active guidelines for end users in numismatic collections [31]. Discussion and feedback was sought in a team discussion with four numismatic experts. All methods used in this case study

\footnotetext{
${ }^{2}$ Personal communication Dr. Richard Abdy, British Museum, Personal Communication from the $\mathrm{COSCH}$ Roman Case study meeting on 22 June 2016 at University College London.
}

were presented and discussed to check that they met requirements in real world numismatic collections [3].

A costing of the time and budget used for this study and a technical report was delivered by each collaborator to the case study leader. The following elements are relevant to costing a project such as this: cost and running time of the hardware and software licenses as well as highly skilled and experienced operator time including time spent on preparation, data acquisition, data processing, reporting and data presentation, as well as data archiving. In some instances, development time for prototype software and hardware should be taken into account. As this was an EU network project with experimental character, all collaborators in this project gave their time and the use of the technical equipment for free, only indicative costs could be collected.

When presented to the numismatic experts, not all methods and technologies employed were perceived affordable in terms of time and cost for numismatic collections, but nevertheless results could be applicable in single cases. The meeting inspired visions for new workflows and future virtual numismatic presentation. 


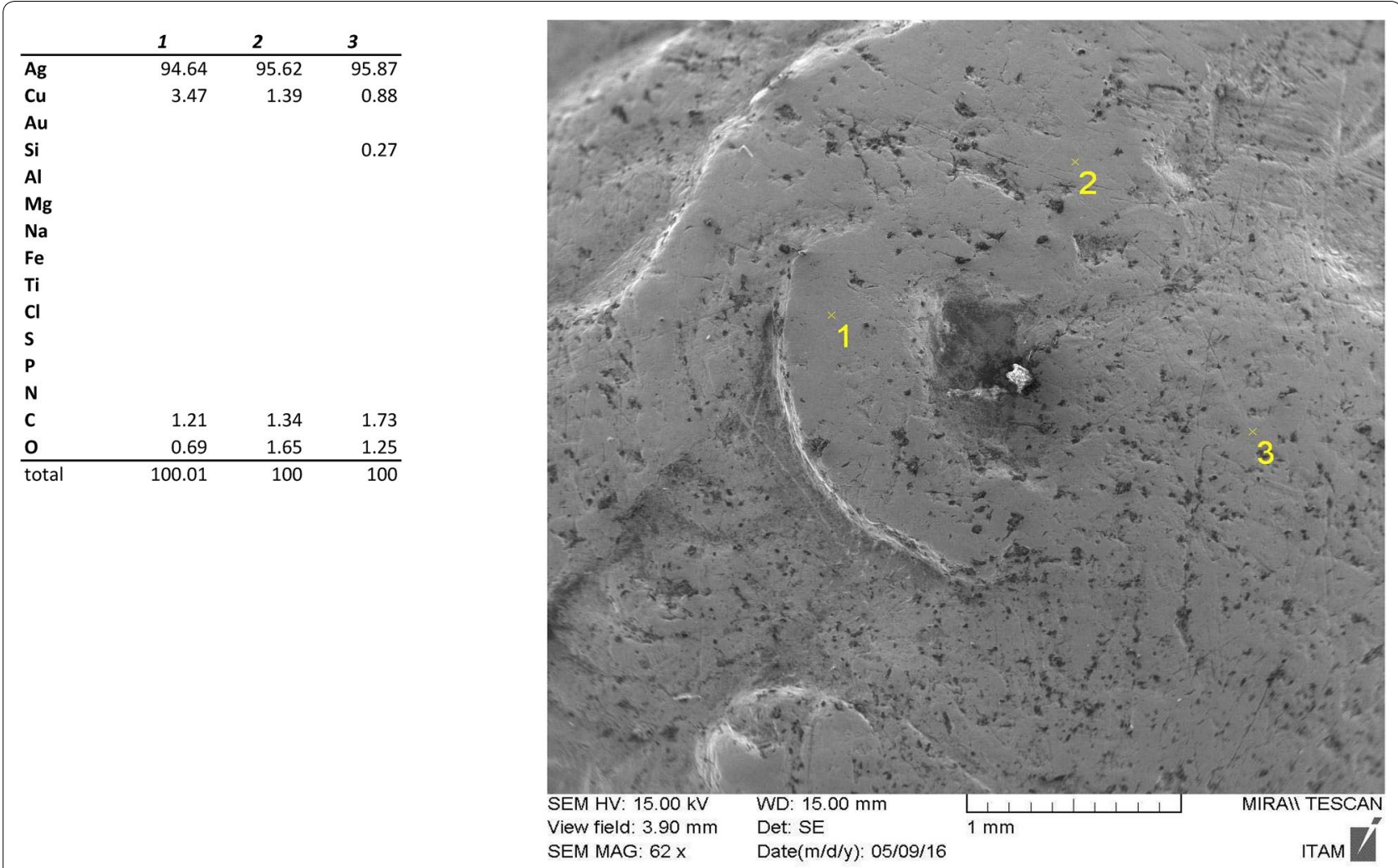

Fig. 17 SEM sampling results for elemental analysis on three spots, SEM surface image of coin A obverse, detail Favstinas' ear (Veronika Koudelková, ITAM)

\section{Review of ongoing research for automated coin classification}

Additionally to the methods used in this study on only two coins, 2D images and 3D images of coin collections can both be used to classify coins. This following section will give a brief insight of ongoing research for the automation of coin classification, interpretation, and metadata extraction for databases.

Methods from automated coin image analysis in computer vision have been used for automated image recognition, based on feature extraction and segmentation of 2000 coins was presented in 2007 [32] and to an automation coin attribution system using image analysis by locally biased directional histograms in 2010 [19]. Zambanini used 3D structured light scanning on a set of 25 coins, to produce metric three-dimensional surface models in colour and geometry, which can overcome limitations of $2 \mathrm{D}$ image recording with regards to specularity of the metal surface [33]. Zambanini and Kampel further proposed a classifier-free procedure for automated coin classification based on 2D image matching based on the SIFT operator (scale-invariant feature transform) in 2011, [34] and [35]. Huber-Moerk described the automated classification and identification of modern and ancient coins based on the analysis of 2D shapes and 3D shapes on a set of 12,000 coins [36]. Kavelar et al. review existing methods for coin classification in detail, including OCR text recognition, and propose coin classification through extraction of legends of Roman Republican Coins by the SIFT descriptor in 2014 [37]. In 2012, Arandjelović proposes a method to automatically extract information from coins from a single photograph by recognising a denarius, extracting the legends and producing a metadata set to enable laymen to report finds to authorities, here to the 'UK portable antiquities scheme' [38]. In 2014, Kim and Pavlovic propose a method directly handles the spatial location of the visual feature to encode the image from existing image-based data [39]. Anwar et al. describe a method for Ancient Coin Classification Using Reverse Motif Recognition for image-based classification of Roman Republican coins in 2015 [40].

Ongoing research should be observed by the interested stakeholders in numismatics. 

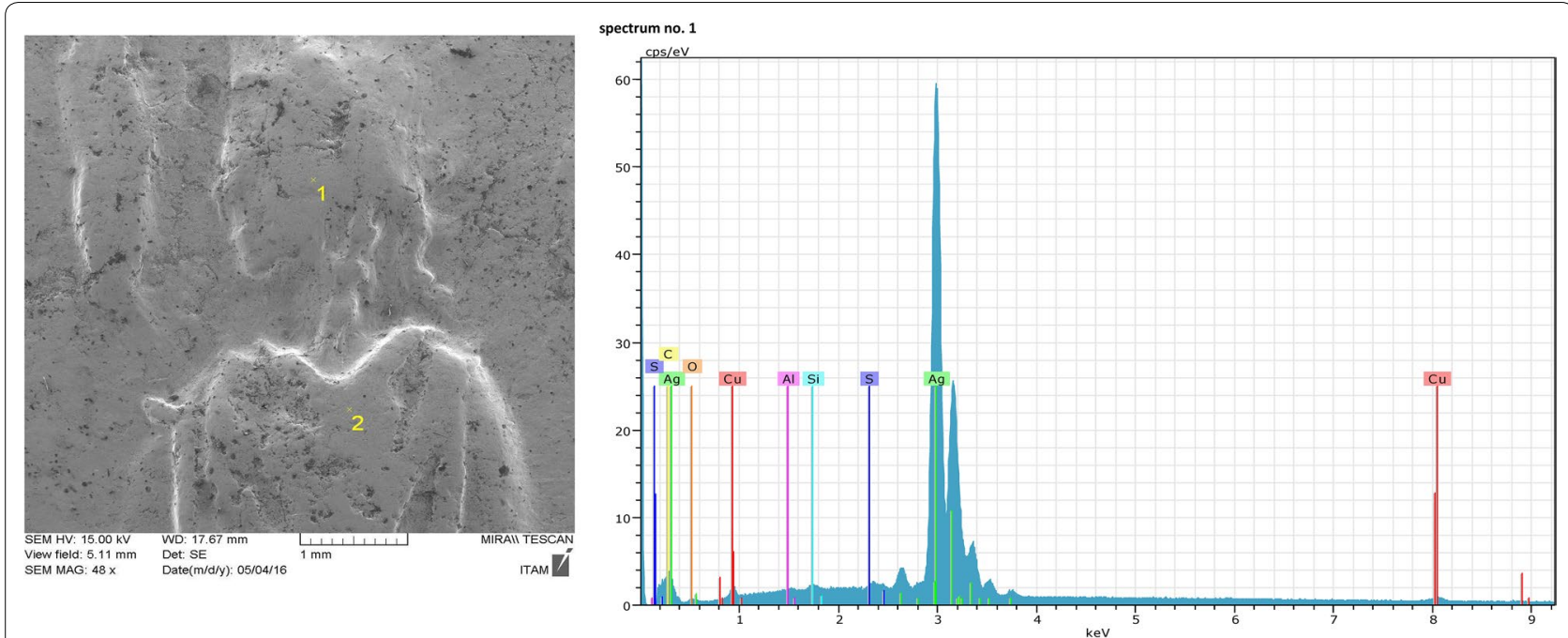

Fig. 18 Close-up SEM surface image of coin B obverse on the ear of Favstina. Yellow numbers indicate sampling spots for elemental analysis (Veronika Koudelková, ITAM)
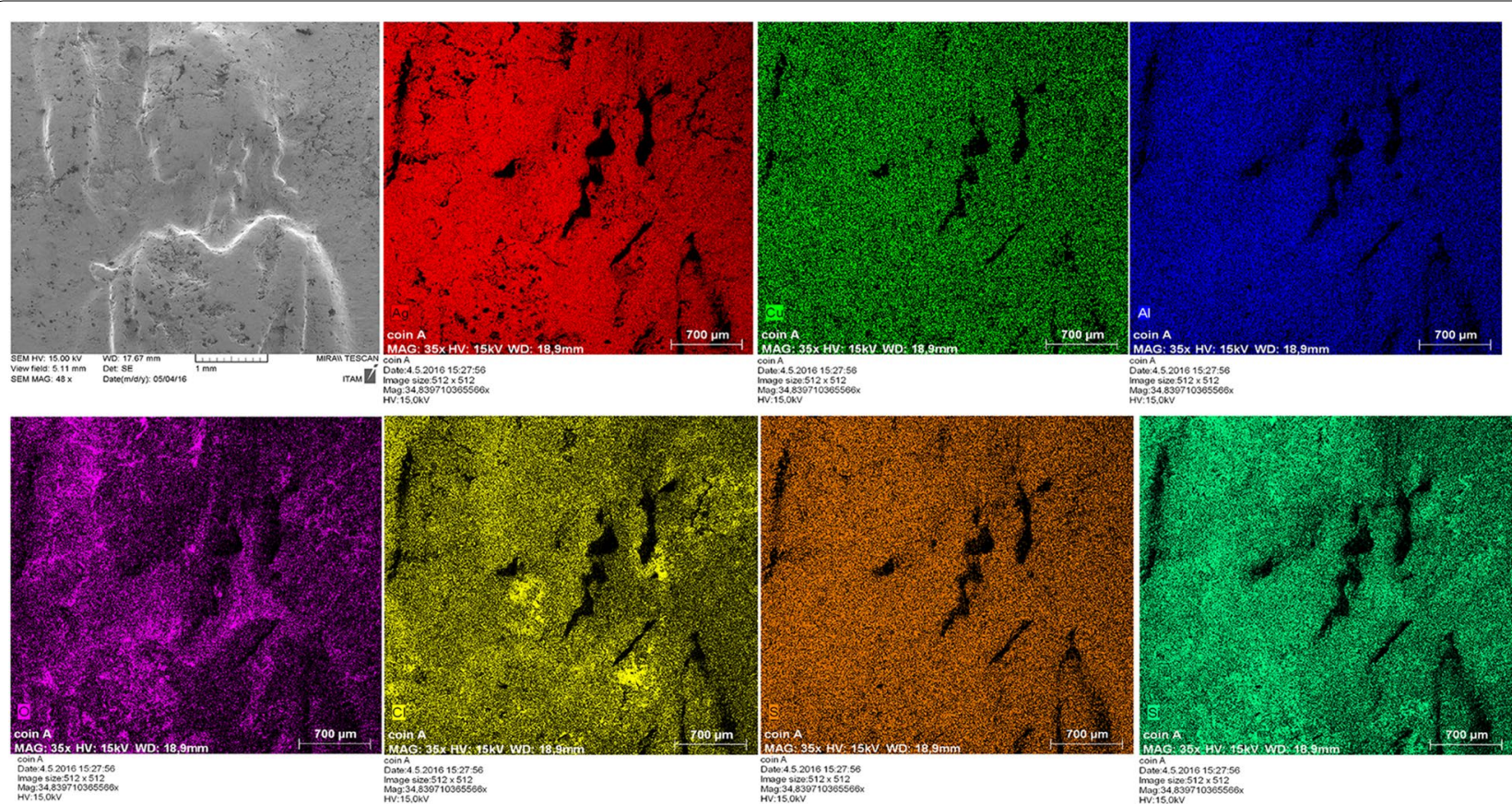

Fig. 19 Spectra from EPMA of coin B. Measurement spots indicated in Fig. 18 (Veronika Koudelková, ITAM)

\section{Conclusion}

The project has produced a comprehensive study using a multi-modal approach using a wide range of methods and technologies used for studying ancient coins on the example of two Roman coins. Optical imaging technologies are mostly well-established applications and show a range of results regarding resolution, accuracy, and precision. 3D digital models may enable the extraction of additional features for object characterization which are not available in 2D (e.g. deviation on the coin's surface morphology, 3D surface area and volume measurements, cross-sections), to their quantitative characterization and analysis. Although a 3D digital model does not provide a complete picture of the object, 
it should be understood as a powerful tool-potentially, with valid data-for visualisation and cultural heritage research, and complementary to other measurement methods [29]. Overall, the analytical methods used in this case study contributed to a holistic knowledge of the coins at different scales and with different types of information.

Whilst the wide adoption of all scientific methods mentioned in this study might be beyond the financial means of many numismatic collections, this project should offer guidance to those researchers who may find it useful to select specific technologies for their own research on coins. The results indicate the feasibility of such methods for museum documentation and as contribution to scientific examination of coins in general. The target beneficiaries of these applications would be numismatic researchers and scientists, historians, collectors, conservators and educators.

In a time where user interfaces become more accessible, software becomes increasingly open-source, and recording technologies more affordable, the outlook for the future is the integration of the workflows towards an automated acquisition and analysis of numismatic collections to make them more accessible for education and research via digital repositories.

\section{Additional files}

Additional file 1: Film S1. Demonstration of 3D Surface model from Photometric Stereo (Lindsay W. MacDonald, UCL).

Additional file 2: Film S2. Demonstration of 3D surface model from photogrammetry/structure from motion (Aurore Mathys, RBINS).

Additional file 3: Film S3. Demonstration of 3D surface model from RTI (Vera Moitinho de Almeida).

Additional file 4: Film S4. Demonstration of X-ray microtomography through Coin A, animation of slices (Miroslav Hain, SAV).

\begin{abstract}
Abbreviations
2D: two-dimensional; 3D: three-dimensional; \%Ag: percentage of the chemical element silver; $\mathrm{COSCH}$ : Colour and Space in Cultural Heritage (Name of EU COST Action: TD1201); DSLR: digital single reflex camera; EDX: EnergyDispersive X-ray Spectroscopy; EMPA: Electron MicroProbe Analysis; GSD: ground sampling distance; Microns: micrometres $(\mu \mathrm{m})$; PTM: polynomial texture mapping; RBINS: Royal Belgium Institute of Natural Sciences; RTI: reflectance transformation imaging; SEM: Scanning Electron Microscopy; UCL: University College London; X-ray $\mu \mathrm{ct} /$ microCT: X-ray microtomography; XRF: X-ray fluorescence.
\end{abstract}

\footnotetext{
Authors' contributions

$\mathrm{MH}$, LWM and JV have jointly written this article, whilst the data described in this article was collected and interpreted by all participants of the case study including the authors (see Acknowledgements). Consent for the use of all material in this article has been given by the participating partners of the $\mathrm{COSCH}$ Roman Coins case study. Single contributors for research results and graphics are acknowledged for each image and data representation. All authors read and approved the final manuscript.
}

\begin{abstract}
Author details
${ }^{1}$ Digital Technologies in Heritage Conservation, Institute of Archaeology, Heritage Conservation and Art History, Otto-Friedrich University of Bamberg, Am Zwinger 4, 96047 Bamberg, Germany. ${ }^{2}$ 3DIMPact Research Group (3D Imaging, Metrology and Photogrammetry Applied Coordinate Technologies), Department of Civil, Environmental and Geomatic Engineering, University College London (UCL), Gower Street, London WC1E 6BT, UK. ${ }^{3}$ Institute of Theoretical and Applied Mechanics of the Academy of Sciences of the Czech Republic (ITAM), Prosecká 809/76, 19000 Prague 9, Czech Republic.
\end{abstract}

\section{Acknowledgements}

The voluntary participation of many individuals in the COSCH Roman coin study is gratefully acknowledged. Most grateful thanks are extended to: Dr. Vera Moitinho de Almeida, Institute for the Study of Ancient Culture (IKAnt), Austrian Academy of Sciences (ÖAW) and Quantitative Archaeology Lab, Universitat Autònoma de Barcelona, Spain, for providing intense help and input as well as for reviewing this article. Further thanks are extended to the participants of this case study: Dr. Anna Bentkowska-Kafel, Department of Digital Humanities, King's College London, UK (lead of the project); Dr. Miroslav Hain, Department of Optoelectronic Measuring Methods, Institute of Measurement Science, Slovak Academy of Sciences, Bratislava, Slovakia (SAV); Eryk Bunsch, Laboratory for 3D Documentation, Museum of King Jan III's Palace at Wilanów, Warszawa, Poland; Dr. Julio M. del Hoyo Melendez, Laboratory of Analysis and Non-Destructive Investigation of Heritage Objects, National Museum in Kraków, Poland; Aurore Mathys of Scientific Heritage, Royal Belgian Museum of Natural Sciences, Brussels (RBINS), and the Royal Museum of Central Africa, Tervuren, Belgium; Dr. Dirk Rieke-Zapp, AICON 3D Systems GmbH, Meersburg, Germany; Professor Robert Sitnik of the Institute of Micromechanics and Photonics, Faculty of Mechatronics, Warsaw University of Technology, Poland, and for further data collection and analysis Ms. Veronika Koudelková from of the Institute of Theoretical and Applied Mechanics of the Academy of Sciences of the Czech Republic, Prague (ITAM).

The study was monitored and advised by Dr. Christian Degrigny of the Haute Êcole Arc Conservation-restauration, Neuchâtel, Switzerland, the $\mathrm{COSCH}$ Steering Committee, and the wider $\mathrm{COSCH}$ community.

Furthermore we would like to thank museum staff and academics who offered generous advice and/or facilitated research, including: Dr. Richard Abdy, Curator of Roman Coins, Coinage of the Roman Empire, Coins and Medals, British Museum, London, UK; Alexandra Baldwin and Pippa Pearce, Conservation and Scientific Research, and Eleanor Ghey, Portable Antiquities and Treasure, both also at the British Museum, London; Julian MC Bowsher, FSA, Senior Archaeologist and Roman coin specialist, Research and Education, Museum of London Archaeology, London, UK; Dr. Bogdan Constantinescu, National Institute of Nuclear Physics and Engineering, Bucharest, Romania; Professor Graeme Earl, Digital Humanities at Kings' College London , and Professor Kirk Martinez, Electronics and Computer Science, at the University of Southampton, UK. Dr. Vasiliki Kassianidou and Dr. Andreas Charalambous, Archaeological Research Unit (ARU), University of Cyprus. Dr. Julio M. del Hoyo Melendez wishes to acknowledge communication with Dr. Matthew Ponting, of Archaeology, Classics and Egyptology, University of Liverpool, UK.

\section{Competing interests}

The authors declare that they have no competing interests.

\section{Availability of data and materials}

The investigation was carried out between September 2014 and October 2016. A comprehensive account and discussion is available on the dedicated website above with images of technical set-up, images, tables and 3D datasets of the Roman Coins project and associated reports. The dataset(s) and tables supporting the conclusions of this article are available on the Roman Coins case study publications and website, https://coschromancoins.wordpress.com [22] (see also video with Additional files 1, 2, 3, 4).

More information about the EU-Cost action is available on the $\mathrm{COSCH}$ project website is at: http://www.cosch.info/.

\section{Funding}

This two-year study (2014-2016) was undertaken by a group of scientists, cultural heritage researchers, conservators and museum professionals 
participating in the European network, Colour and Space in Cultural Heritage, supported by the European Cooperation in Science and Technology between 2013 and 2016. This transdomain COST Action (TD1201) is exploring highresolution optical techniques, defining good practice and open standards for state-of-the-art documentation of material cultural heritage. The study of Roman coins was conducted on a voluntary basis and benefitted mainly from the support of participating institutions. Some activities were embedded in routine research and teaching of participating institutions.

\section{Publisher's Note}

Springer Nature remains neutral with regard to jurisdictional claims in published maps and institutional affiliations.

Received: 12 March 2017 Accepted: 29 November 2017

Published online: 08 February 2018

\section{References}

1. Kogou S, Lucian A, Bellesia S, Burgio L, Bailey K, Brooks C, et al. A holistic multimodal approach to the non-invasive analysis of watercolour paintings. Appl Phys A. 2015;121(3):999-1014

2. COSCH. Homepage of COST-action TD1201: colour and space in cultural heritage (COSCH). 2016. http://www.cosch.info/. Accessed 21 July 2017.

3. Bentkowska-Kafel A, Moitinho de Almeida V, MacDonald LW, del Hoyo Melendez J, Mathys A. Beyond photography. An interdisciplinary exploratory case study in the recording and examination of Roman silver coins. In: Bentkowska-Kafel A, MacDonald LW, editors. Digital techniques for documenting and preserving cultural heritage. Plymouth: ARC Humanities Press; 2017.

4. Mudge M, Voutaz J-P, Schroer C, Lum M. Reflection transformation imaging and virtual representations of coins from the hospice of the grand St. Bernard. In: Proceedings of the 6th international symposium on virtual reality, archaeology and cultural heritage (VAST). Aire-la-Ville: Eurographics Assoc.; 2005. p. 29-39. (Eurographics symposium proceedings)

5. Howgego CJ. The potential for image analysis in numismatics. In: Bowman AK, Brady M, editors. Images and artefacts of the ancient world. 1st ed. Oxford: British Academy by Oxford University Press; 2005. p. 109-13. http://britishacademy.universitypressscholarship.com/view/10.5871/ bacad/9780197262962.001.0001/upso-9780197262962-chapter-12. Accessed 22 Nov 2017

6. Goodman M. Numismatic photography. California: Zyrus Press; 2008.

7. Hoberman G. The art of coins and their photography: an illustrated photographic treatise with an introduction to numismatics. London: Lund Humphri; 1981.

8. Malzbender T, Gelb D, Wolters H, Hewlett-Packard Laboratories. Polynomial texture maps. 2001. http://www.hpl.hp.com/research/ptm/papers/ ptm.pdf. Accessed 28 Feb 2017.

9. Palma G, Siotto E, Proesmans M, Batino S, Baldassarri M, Scopigno R. Telling the story of ancient coins by means of interactive RTI images visualization. Archaeol Digital Era. 2014;7:177-85.

10. Piquette KE. Documenting early Egyptian imagery: analysing past technologies and materialities with the aid of reflectance transformation imaging (RTI). In: Graff G, Jimenez-Serrano A, Bailly M, editors. Prehistories of writing: iconography, graphic practices and the forming process of writing in predynastic Egypt. Aix-en-Provence: Presses Universtaires de Provence; 2010. p. 89-112 (Préhistoires méditerranéennes)

11. MacDonald L, Moitinho de Almeida V, Hess M. Three-dimensional reconstruction of Roman coins from photometric image sets. J Electron Imaging. 2017;26(1, Special Section on Image Processing for Cultural Heritage (24)):011017-1--20.

12. Brecko J, Mathys A, Dekoninck W, Leponce M, VandenSpiegel D, Semal P. Focus stacking: comparing commercial top-end set-ups with a semiautomatic low budget approach. A possible solution for mass digitization of type specimens. ZooKeys. 2014;464:1-23.

13. Pieper RJ, Korpel A. Image processing for extended depth of field. Appl Opt. 1983;22(10):1449-53.
14. Robson S, MacDonald S, Were G, Hess M. 3D recording and museums. In: Warwick C, Terras M, Nyhan J, editors. Digital humanities in practice. 1st ed. London: Facet Publishing; 2012. p. 91-115.

15. Hess M, Robson S. 3D colour imaging for cultural heritage artefacts. Int Arch Photogramm Remote Sens Spat Inf Sci. 2010;XXXVIII(Part 5):288-92.

16. Mathys A, Brecko J, Semal P. Comparing 3D digitizing technologies: what are the differences? In: Digital Heritage International Congress (Digital Heritage), vol. 1. IEEE; 2013, pp. 201-204.

17. Moitinho de Almeida V, Rieke-Zapp D. Generación de datos con sistemas ópticos de medición de corto alcance. In: Jiménez-Badillo D, editor. Arqueología Computacional Nuevos enfoques para el análisis y la difusión del patrimonio cultural. Ciudad de México: Instituto Nacional de Antropología e Historia (INAH); 2017.

18. Bathow C, Breuckmann B, Scopigno R. Verification and acceptance test for high definition 3D surface scanners. In: 11 th VAST international symposium on virtual reality, archaeology and cultural heritage. Paris: Eurographics Association; 2010. p. 9-16.

19. Bozzini B, Gianoncelli A, Mele C, Siciliano A, Mancini L. Electrochemical reconstruction of a heavily corroded Tarentum hemiobolus silver coin: a study based on microfocus X-ray computed microtomography. J Archaeol Sci. 2014;52:24-30

20. Goldstein Jl, Newbury DE, Echlin P, Joy DC, Lyman CE, Lifshin E, et al. Scanning electron microscopy and X-ray microanalysis. 3rd ed. London: Kluwer Academic/Plenum Publishers; 2003. p. xix + 689.

21. del Hoyo-Meléndez JM, Świt P, Matosz M, Woźniak M, Klisińska-Kopacz A, Bratasz $Ł$. Micro-XRF analysis of silver coins from medieval Poland. Nucl Instrum Methods Phys Res Sect B. 2015;349:6-16.

22. Bentkowska-Kafel A, Mathys A, Hain M, Hess M, del Hoyo Melendez, MacDonald L, et al. Roman coins-COSCH Case Study. The website contains detailed and referenced sections for the technologies used in the multimodal imaging case study. Roman coins. 2016. https://coschromancoins. wordpress.com/. Accessed 19 July 2017

23. Moitinho de Almeida V, Barceló JA. 3D Scanning and Computer Simulation of Archaeological Artefacts. In: Castillo A, editor. Proceedings of the 1st international conference on best practices in world heritage: archaeology. Menorca; 2012. p. 384-99. https://polipapers.upv.es/index. php/var/article/view/4277/0. Accessed 19 Jan 2017.

24. Santos P, Ritz M, Fuhrmann C, Monroy R, Schmedt H, Tausch R, et al. Acceleration of 3D Mass Digitization Processes: Recent Advances and Challenges. In: Ioannides M, Magnenat-Thalmann N, Papagiannakis $\mathrm{G}$, editors. Mixed reality and gamification for cultural heritage. Berlin: Springer International Publishing; 2017. p. 99-128. http://link.springer. com/chapter/10.1007/978-3-319-49607-8_4. Acessed 2 May 2017.

25. BentkowskaKafel A, Denard H, Baker D, editors. The London charter for the computer-based visualisation of cultural heritage (Version 2.1, February 2009). Aldershot: Ashgate Publishing Ltd; 2012.

26. Denard H. A new introduction to the London Charter. In: BentkowskaKafel A, Denard H, Baker D, editors. Paradata and transparency in virtual heritage. Aldershot: Ashgate Publishing Ltd; 2012; p. 57-72.

27. ICOM, CIDOC CRM Special Interest Group. Definition of the CIDOC conceptual reference model-version 5.0.1-March 2009. CIDOC CRM Homepage. 2009. http://www.cidoc-crm.org/index.html. Accessed 19 July 2017.

28. 3D-Coform, Arnold D. D.2.1 —initial version of "user requirement analysis and functional specifications" - tools and expertise for 3D collection formation (Public Deliverables). 2009. http://www.3d-coform.eu/index. php/downloads. Accessed 2 Feb 2015.

29. Moitinho de Almeida V. Towards functional analysis of archaeological objects through reverse engineering processes (Doctoral thesis). BarceIona: Universitat Autònoma de Barcelona, Departament de Prehistòria; 2013. http://www.tdx.cat/handle/10803/129161. Accessed 28 Feb 2017

30. Hess M. Online survey about current use of $3 \mathrm{D}$ imaging and its user requirements in cultural heritage institutions. In: 2015 Digital Heritage, vol. 2. Granada: IEEE Xplore Digital Library; 2015. p. 333-338. http://discovery.ucl.ac.uk/1471673/. Accessed 10 May 2016.

31. Bentkowska-Kafel A, del Hoyo Melendez J, Macdonald LW, Mathys A, Moitinho de Almeida V. Colour and space in cultural heritage in 6Ds. The interdisciplinary connections. In: Proceedings of the 43rd conference on 
computer applications and quantitative methods in archaeology (CAA). Siena: Archaeopress, Oxford; 2015. p. 953-62.

32. Reisert $\mathrm{M}$, Ronneberger $\mathrm{O}$, Burkhardt $\mathrm{H}$. A fast and reliable coin recognition system. In: Joint Pattern Recognition Symposium. Berlin: Springer; 2007. p. 415-424.

33. Zambanini S, Schlapke M, Kampel M, Müller A. Historical coins in 3D: acquisition and numismatic applications. In: Proceedings of the international symposium on virtual reality, archaeology and cultural heritage (VAST). 2009. p. 49-52. http://www.caa.tuwien.ac.at/cvl/wp-content/ uploads/2014/12/vast09.pdf. Accessed 26 Feb 2017.

34. Zambanini $S$, Kampel M. Automatic coin classification by image matching. In: Dellepiane M, Niccolucci F, Serna SP, Rushmeier H, Van Gool L, editors. The 12th International Symposium on Virtual Reality, Archeology and Cultural Heritage VAST. Eurographics Association; 2011.

35. Zambanini S, Kavelar A, Kampel M. Classifying ancient coins by local feature matching and pairwise geometric consistency evaluation. In: 2014 22nd international conference on pattern recognition (icpr). Los Alamitos: leee Computer Soc; 2014. p. 3032-7.

36. Huber-Mörk R, Nölle M, Rubik M, Hödlmoser M, Kampel M, Zambanini S. Automatic coin classification and identification. In: Kypraios I, editor.
Advances in object recognition systems. Rijeka: InTech; 2012. p. 127-54. https://www.intechopen.com/books/advances-in-object-recognitionsystems/automatic-coin-classification-and-identification. Accessed 26 Feb 2017.

37. Kavelar A, Zambanini S, Kampel M. Reading the legends of Roman Republican coins. J Comput Cult Herit. 2014;7(1):5:1-20.

38. Arandjelović $\mathrm{O}$. Reading ancient coins: automatically identifying denarii using obverse legend seeded retrieval. In: Computer vision_ECCV 2012. Berlin: Springer; 2012. p. 317-30. (Lecture Notes in Computer Science). https://link.springer.com/chapter/10.1007/978-3-642-33765-9_23. Accessed 22 July 2017.

39. Kim J, Pavlovic V. Ancient coin recognition based on spatial coding. In: Pattern Recognition (ICPR) 22nd International conference on Pattern Recognition. IEEE; 2014. p. 321-326.

40. Anwar H, Zambanini S, Kampel M, Vondrovec K. Ancient coin classification using reverse motif recognition: image-based classification of roman republican coins. IEEE Signal Process Mag. 2015;32(4):64-74.

\section{Submit your manuscript to a SpringerOpen ${ }^{\circ}$ journal and benefit from:}

- Convenient online submission

- Rigorous peer review

- Open access: articles freely available online

- High visibility within the field

- Retaining the copyright to your article

Submit your next manuscript at $\boldsymbol{s p r i n g e r o p e n . c o m ~}$ 